\title{
Review Article \\ Immunogenic Cell Death: Can It Be Exploited in PhotoDynamic Therapy for Cancer?
}

\author{
Elisa Panzarini, Valentina Inguscio, and Luciana Dini \\ Department of Biological and Environmental Science and Technology (Di.S.Te.B.A.), University of Salento, \\ Via per Monteroni, 73100 Lecce, Italy \\ Correspondence should be addressed to Luciana Dini; luciana.dini@unisalento.it
}

Received 23 July 2012; Revised 18 September 2012; Accepted 1 October 2012

Academic Editor: Kristjan Plaetzer

Copyright (C) 2013 Elisa Panzarini et al. This is an open access article distributed under the Creative Commons Attribution License, which permits unrestricted use, distribution, and reproduction in any medium, provided the original work is properly cited.

\begin{abstract}
Immunogenic Cell Death (ICD) could represent the keystone in cancer management since tumor cell death induction is crucial as well as the control of cancer cells revival after neoplastic treatment. In this context, the immune system plays a fundamental role. The concept of Damage-Associated Molecular Patterns (DAMPs) has been proposed to explain the immunogenic potential of stressed or dying/dead cells. ICD relies on DAMPs released by or exposed on dying cells. Once released, DAMPs are sensed by immune cells, in particular Dendritic Cells (DCs), acting as activators of Antigen-Presenting Cells (APCs), that in turn stimulate both innate and adaptive immunity. On the other hand, by exposing DAMPs, dying cancer cells change their surface composition, recently indicated as vital for the stimulation of the host immune system and the control of residual ill cells. It is well established that PhotoDynamic Therapy (PDT) for cancer treatment ignites the immune system to elicit a specific antitumor immunity, probably linked to its ability in inducing exposure/release of certain DAMPs, as recently suggested. In the present paper, we discuss the DAMPs associated with PDT and their role in the crossroad between cancer cell death and immunogenicity in PDT.
\end{abstract}

\section{Introduction}

The plain success of cancer therapies crucially depends on the synergic interaction between immune cells and dying/dead cancer cells. The ideal cancer treatment should merge the direct cytotoxic action on tumor cells with potent immunostimulatory effects based on the recognition of molecular immunogenic determinants on dying cells by immune cells. Indeed, anticancer immune responses may contribute to the control of the neoplastic disease after cancer modalities since they help to eliminate residual cancer cells or maintain micrometastases in a stage of dormancy. The capability of a cancer treatment to elicit Immunogenic Cell Death is clinically relevant since it is associated with an anticancer immune response that reinforces the therapeutic effect of the therapy. The immunogenicity of the dying cancer cells involves subtle changes in their surface proteome and the secretion of soluble molecules known as Damage-Associated Molecular Patterns (DAMPs) allowing their immunogenic recognition by immune effectors.
In recent times, more and more efforts are addressed to associate particular DAMPs with a specific cell death pathway or with particular stress agents able to induce Immunogenic Cell Death (ICD) in cancer cells. One such therapeutic modality certainly associated with DAMPs is PhotoDynamic Therapy (PDT). In the present paper, we collect data regarding DAMPs related to PDT, primarily focusing on the ability of these molecules to function as ICD effectors in PDT.

\section{Emerging Hallmarks of Cancer}

During their evolution to the malignant state, tumor cells progressively evolve multiple ploys to carry out their intrinsic fateful program. Particularly, cancer cells acquire six distinctive and complementary biological capabilities allowing tumor growth and metastatic dissemination. These include self-sufficiency in growth signals, insensitivity to growth suppressors, circumventing cell death mechanisms, limitless replicative potential, sustained angiogenesis, and tissue 
invasion and metastasis [1]. Cancer cells do not need stimulation from external growth factors to grow and divide since they can generate their own growth signals sustaining chronic proliferation. Unlike normal cells whose growth is kept under control by inhibitors in the surrounding environment, in the extracellular matrix and on the surface of neighboring cells, tumor cells are generally resistant to growth-preventing signals becoming masters of their own destinies. They are able to bypass apoptosis, the preferential form of Programmed Cell Death (PCD) induced by conventional cancer therapies, by the loss of Tumor Protein 53 (TP53) tumor suppressor function, the upregulation of antiapoptotic regulators ( $\mathrm{Bcl}-2, \mathrm{Bcl}-\mathrm{xL})$ or of survival signals (Igf1/2), the downregulation of proapoptotic factors (Bax, Bim, Puma), or the short-circuiting of the extrinsic ligand-induced death pathway. Normal cells undergo a limited number of successive cell growth-anddivision cycles, since their proliferation is subjected to two distinct barriers: senescence, a viable state characterized by an irreversible arrest in proliferation limiting the lifespan of mammalian cells, and crisis, which involves cell death. On the other hand, cancer cells escape these barriers and they are capable of indefinite growth and division (immortality). In fact, the immortal cells present damaged telomeres, the regions of repetitive nucleotide sequences at each end of a chromosome, that are centrally involved in this unlimited proliferation capability [2]. In order to progress, cancer cells must turn on a blood supply, generated by the process of angiogenesis, ensuring a continual provision of oxygen and other nutrients. Angiogenesis is balanced by inducers, such as vascular endothelial growth factor (VEGF) and acidic and basic fibroblast growth factor (FGF 1/2), and inhibitors, including thrombospondin-1. Thrombospondin1 is regulated by p53, therefore the loss of p53 can allow angiogenesis. Tumor cells can migrate from their origin site to invade surrounding tissue and metastasize to distant body areas through a multistep process, referred to as invasionmetastasis cascade [3], characterized by a succession of cellbiologic changes. These include (1) local invasion, then (2) intravasation by cancer cells into nearby blood and lymphatic vessels, (3) transit of cancer cells through the lymphatic and hematogenous systems, followed by (4) escape of cancer cells from the lumina of such vessels into the parenchyma of distant tissues (extravasation), (5) the formation of small nodules of cancer cells (micrometastases), and finally the growth of micrometastatic lesions into (6) macroscopic tumors (colonization).

The acquisition of the six functional capabilities allowing cancer cells to survive, proliferate, and disseminate is made possible by two enabling characteristics: genome instability, which generates random mutations, such as chromosomal rearrangements, driving tumor progression; and inflammation by innate immune cells, which results in tumor-promoting consequences. Indeed, the immune system both antagonizes and enhances tumor development and progression, playing dichotomous roles. In the last decade two emerging hallmarks have been added to this list: reprogramming of energy metabolism in order to most effectively support neoplastic proliferation and evading immune destruction by $\mathrm{T}$ and $\mathrm{B}$ lymphocytes, macrophages, and natural killer (NK) cells. Particularly, the abilities to replicate in a chronically inflamed microenvironment, to evade immune recognition, and to suppress immune reactivity enable neoplastic cells to escape the immune responses [1].

The poor antitumor immunity and the escape to the innate and adaptive immune responses are based on the downregulation of tumor cell Major Histocompatibility Complex (MHC) I and costimulatory molecules, alteration of DCs and macrophages function in tumor tissue, regulatory $\mathrm{T}$ cells induction, and tumor-mediated immune cell death [4]. Besides, tumor resistance may also be a consequence of the altered expression of oncogene-coded proteins, as demonstrated in ovarian carcinoma-derived cells expressing low levels of HLA class I surface antigens and decreased or absent HLA-A2 expression [5]. Also dysregulation of various components of the MHC class I Antigen Processing Machinery (APM) may avoid the recognition of tumor cells by CD8+ T cells [6].

The long-standing concept of immunosurveillance implying the constant monitoring of cells and tissues by an ever-alert immune system able to recognize and remove nascent transformed cells [7] has been abandoned in favor of the cancer immunosurveillance acting as a component of the cancer immunoediting. Particularly, cancer immunoediting, which represents a refinement of the original cancer immunosurveillance hypothesis, plays a dual role in promoting host protection against cancer and facilitating tumor escape from immune destruction. It is responsible for both eliminating tumors and sculpting the immunogenic phenotypes of tumors as they develop. This process consists of three phases that are collectively denoted "the three Es of cancer immunoediting": elimination, equilibrium, and escape. Elimination corresponds to immunosurveillance; equilibrium represents the process by which the immune system iteratively selects and/or promotes the generation of tumor cell variants with increasing capacities to survive immune attack; escape is the process wherein the immunologically sculpted tumor expands in an uncontrolled manner in the immunocompetent host [8].

In the clinical management of the neoplastic disease, the ideal therapeutic strategy should combine the restoration of cancer cell death and the enhancement of the immunological recognition of tumor cells [9]. This may be achieved by avoiding cancer modalities mediating immunosuppressive side effects and favoring therapies able to induce ICD, which represents a novel possibility to attack neoplasia with the specificity of the immune system [10].

It is still unclear under which circumstances cellular demise induces an immune response against dying tumor cells or rather it remains immunologically silent. The classical notion that apoptotic cell death is poorly immunogenic (or even tolerogenic), whereas necrotic cell death is truly immunogenic has been recently invalidated since it does not withstand experimental verification, at least in models of tumor vaccination $[11,12]$. Indeed, tumor vaccination studies in mice demonstrate that some apoptosis-inducing regimens induce immune-dependent tumor regression whereas others do not, suggesting an unsuspected heterogeneity in 
the biochemical pathways leading to apoptotic cell death [13].

The immunogenicity of dying cells is mediated by changes in the composition of the cell surface and the secretion of soluble molecules allowing the immune effectors, primarily dendritic cells (DCs), to sense immunogenicity [14]. Intracellular molecules, categorized as Damage-Associated Molecular Patterns (DAMPs), also known as alarmins, normally hidden within live cells, are released from or exposed at the surface of dying cell determining DCs activation and maturation, antigen processing, and $\mathrm{T}$ cell activation (see below).

The appealing idea of immunogenic cancer cell death demands screening of newer anticancer agents/modalities capable of sustaining a particular spectrum of DAMPs. Indeed, a chemotherapeutic agent-specific cancer ICD modality presents the potential to induce in vivo an "anticancer vaccine effect" by merging tumor cell kill and antitumor immunity within a single paradigm.

\section{PhotoDynamic Therapy: Basic Principles and Applications}

One recent therapeutic modality endowed with a known association with certain DAMPs is PhotoDynamic Therapy (PDT), a Food and Drug Administration (FDA)-approved clinical protocol for the treatment of several malignant and nonmalignant diseases [15]. PDT presents multiple advantages over "classical" anticancer regimens, such as surgery, ionizing radiation, and chemotherapy: it is minimally invasive, it has low mutagenic potential, low systemic toxicity and it specifically targets tumor areas over normal tissue $[16,17]$.

It is a two-step procedure involving the administration of a tumor-localizing photosensitizer (PS) and its subsequent activation by light of specific wavelength. PDT utilizes the destructive power of Reactive Oxygen Species (ROS) generated via photophysical/photochemical reactions by the interaction between visible light, PS, and tissue molecular oxygen, the three main components of the photodynamic reaction, to elicit cancerous cells obliteration [18].

Efficient photosensitization primarily depends on the PS physico-chemical properties, including chemical purity, selectivity for cancer cells, chemical and physical stability, short time interval between the drug administration and its accumulation within tumor cells, activation at wavelength with optimal tissue penetration, and rapid clearance from normal tissues [19], and it is related to the amount of oxygen within the tumor area that, in turn, depends on the tissue oxygen concentration [20]. Photodynamic treatment also strictly relies on the light source and light delivery, whose choice is affected by tumor location, light dose delivered, and PS used. Lasers, lamps, and Light Emitting Diodes (LED) are all light sources employed in PDT. Conversely to lamps, lasers are typically near-monochromatic enabling the exact selection of wavelengths and the precise application of light. On the other hand, the main characteristics of LED use are price and versatility in light delivery on difficult anatomic area [21].

The photodynamic reaction is based on photophysical and photochemical processes [22]. Upon visible light irradiation, the PS in its ground state is activated to the shortlived single excited state and it can lose its energy by emitting fluorescence or vibrational energy (photophysicalreaction). The excited singlet state PS may also undergo a process known as intersystem crossing to form a relatively longlived excited triplet state (photochemical reaction), which may interact with surrounding molecules resulting in two types of photooxidative reactions exploited in PDT. In type I photochemical reaction, the PS excited triplet state directly reacts with a substrate, such as the cell membrane, and it transfers an electron or hydrogen atom producing radical forms. These intermediates may further react with oxygen to form peroxides, superoxides ions, and hydroxyl radicals (known as ROS), initiating free radical chain reactions. Alternatively, type II photochemical reaction involves the direct transfer of triplet PS energy to molecular oxygen to form excited-state singlet oxygen $\left({ }^{1} \mathrm{O}_{2}\right)$, the most important reactive species in PDT-mediated cytotoxicity [23]. The two types of photochemical reactions can simultaneously occur and their ratio depends on the type of PS, substrate, and oxygen concentration.

PDT-mediated tumor destruction is multifactorial: (1) direct tumor cells killing, (2) vasculature damage, and (3) rapid recruitment and activation of immune cells favoring the development of antitumor adaptive immunity [18, 24, 25].

Particularly, cancer cells can respond to photodynamic injury by initiating a rescue response and/or succumbing to multiple cell deaths. Three distinct mechanisms have been recognized to contribute to $\mathrm{PDT}$-mediated tumor destruction: apoptosis, necrosis, and autophagy [26]. Apoptosis is the preferential PCD induced by the exposure of many photosensitized cell types to toxic agents, such as ROS. Apoptosis can be activated both in a caspases-dependent and independent manner. Particularly, PDT leads to activation of the several apoptotic pathways: extrinsic or death receptor pathway, implying the binding of death ligands to their specific cell surface death receptors (e.g., FasL/FasR, TNF$\alpha /$ TNFR1, Apo3L/DR3, Apo2L/DR4, and Apo2L/DR5) ending in caspase 8 activation; intrinsic or mitochondrial pathway, involving caspase 9 activation and release of cytochrome c into the cytosol; ER stress-mediated pathway, mediating the cleavage of caspase 12; and caspase independent pathway, triggered by mitochondrial proapoptotic proteins, for example, AIF (Apoptosis Inducing Factor) and EndoG (Endonuclease G), able to induce apoptosis without caspase involvement by translocating to the nucleus where they generate DNA fragmentation (reviewed in $[18,26]$ ). Master regulators of apoptotic machinery are Bcl-2 family proteins, comprising both anti- and proapoptotic members [27]. PDT is able to induce photoxidation of $\mathrm{Bcl}-2$ antiapoptotic proteins and activate the proapoptotic members of the family [28].

If apoptosis is the preferential cell death mechanism induced by PDT, a switch from apoptosis to necrosis strictly 
depends on PDT dose in term of light dose and PS concentration. Indeed, high PDT dose tends to cause cell death by necrosis, while low photodynamic regimen induces apoptotic cell death.

The role of autophagy in PDT-treated cells is controversial, since it plays a role in either inhibiting or stimulating cell death following photodynamic treatment $[29,30]$. Although autophagy is generally thought of as a cell survival strategy, the high reactivity of photogenerated ROS can commit tumor cells to their final demise [31]. Generally, autophagy plays a prosurvival role in tumor cells capable of apoptosis; conversely, it promotes cancer cell death in apoptosis-deficient cells.

In some experimental PDT protocols, the specific inhibition of one of these three cell death mechanisms does not impair the activation of the others, suggesting their independent onset in PDT, which is able to ensure a longterm tumor photokilling $[32,33]$.

Tumor eradication is also mediated by strong PDTinduced inflammatory and immune reactions ending in the rapid recruitment of immune cells to neoplastic sites. Several reports suggest the infiltration of lymphocytes, leukocytes, and macrophages into the photosensitized tissue activating an immune response that consequently eliminates surviving cancer cells escaped to the direct PDT effects [34, 35].

The considerable beneficial immunomodulatory potential of PDT represents an exploitable plot in terms of cancer disease management. High-inflammatory PDT regimens induce acute inflammation characterized by increased expression of proinflammatory cytokines [36], adhesion molecules E-selectin and ICAM-1, and the rapid accumulation of leukocytes into the treated tumor area [37]. PDT enhancement of antitumor immunity appears to involve the stimulation of DCs by dying tumor cells [38]. Indeed, the incubation of photosensitized tumor cells with immature DCs induces an enhanced DC maturation, activation, and ability to stimulate $\mathrm{T}$ cell activation [39].

\section{Immunogenic Cell Death: New Concept in Cancer Therapy Outcome}

The intrinsic Achille's heel of conventional cancer regimens, that is, chemotherapy or radiotherapy, relies on their inability to eradicate all tumor cells. However, the knowledge of cancer immune hallmarks could be exploited to stimulate immune system and, consequently, to favour the patient, by designing therapeutic regimens able to elicit the immune reactivity and counteract immune suppression. In fact the immunogenicity of the succumbing tumor cells could drive a strong immune response against cancer cells survived to therapy [40]. Indeed, in response to anthracyclins (e.g., doxorubicin and mitoxantrone), oxaliplatin and ionizing irradiation, cancer cells die triggering a tumor-specific immune responses [41]. Altogether, these observations support the Immunogenic Cell Death (ICD) concept [42]. Particularly, the signals delivered by immunogenic dying cells function as antigens stimulating the crosstalk between DCs and T cells, that in turn mediates immunogenic impetus [43].
4.1. The Effectors of ICD: Alarmins. The relocation, release, and/or plasma membrane exposure of intracellular proteins by dying cancer cells are the key mechanisms in ICD. These intracellular molecules, known as alarmins, are categorized as DAMPs, and they are functionally similar to PathogenAssociated Molecular Patterns (PAMPs), including bacterial and viral nucleic acids, fungal $\beta$-glucan and $\alpha$-mannan cell wall components, the bacterial protein flagellin, components of the peptidoglycan bacterial cell wall, and lipopolysaccharide (LPS) from Gram-negative bacteria [44].

DAMPs are normally retained within healthy cells and are extracellularly relocated in damaged/dying cells acquiring immunostimulatory/immunomodulatory properties when they interact with both intracellular and membrane-bound Pattern-Recognition Receptors (PPRs), for example, RIGI-like receptors (RLRs), the NOD-like receptors (NLRs), and Toll-like receptors (TLRs). The diversity of DAMPs is related to the type of cell death, cell type, and tissue injury [44].

A multitude of immunogenic factors has been identified: Endoplasmic Reticulum (ER) protein calreticulin (CRT) [45], several members of the Heat Shock Proteins (HSPs) family [46-48], High-Mobility Group Box 1 (HMGB1) [49], endstage degradation products (e.g., ATP, DNA and RNA, uric acid) [50-52], S100 proteins [53], and sphingosine [54]. Depending on the stage and relocation place, these molecules can be divided in three groups: (1) DAMPs exposed on plasma membrane; (2) DAMPs secreted extracellularly and (3) DAMPs produced as end-stage degradation products.

Secreted DAMPs can be in turn classified on the basis of the release mechanism: DAMPs passively released (e.g., during necrotic cell death), DAMPs released in a pulsatile manner (e.g., during apoptotic cell death), and DAMPs released by a noncanonical pathway, upon induction by activated immune cells [55].

Moreover, considering origin and mechanisms of action, the proinflammatory DAMPs can be classified as those that directly stimulate the immune cells and those that induce DAMPs generation exerting a bystander effect on extracellular molecules [56].

Furthermore, other signals, regarded as "atypical DAMPs", are being studied as alarmins, like "whole organelle-based danger signals", for example, complete mitochondria able to activate the NLRP3 inflammasome [57, 58], extracellular matrix compounds (e.g., hyaluronan, heparin sulphate, and degraded matrix constituents) [59], and signals/structures not yet fully characterized, for example, tumor cell-derived exosomes $[60,61]$.

In the following paragraphs, we summarize the characteristics and the translocation/release mechanisms of the main DAMPs acting as effectors of ICD.

Calreticulin. Calreticulin (CRT) is a $46 \mathrm{kDa} \mathrm{Ca}^{2+}$-binding protein prevalently located in ER lumen, where it acts in proper folding of proteins, by interacting with ER-resident disulfide isomerase ERp57 and calnexin (CNX) [62], and in $\mathrm{Ca}^{2+}$ homeostasis/signaling regulation [63]. Moreover, in $\mathrm{ER}$, the CRT participates in MHC class I molecule assembly 
and loading of the antigen peptides onto the MHC class I molecule [64].

The CRT also resides in the nuclear envelope lumen, where it regulates nuclear protein transport [65] and signaling via nuclear steroid receptors and integrins [66], and in the cytoplasm. Probably, cytoplasmic CRT regulates cell adhesion, translation, gene expression, and nuclear export [67].

It has been demonstrated that CRT is also involved in cardiac development and adipocyte cells differentiation [68].

The dynamic exposure of CRT (ecto-CRT) on plasma membrane marks the cell for ICD [45]. Few studies have been performed in order to understand the mechanism regulating CRT translocation, that seems to unfold through three modules, that is, ER stress induction, apoptosis trigger, CRT translocation. Ecto-CRT translocation depends on the stress inducer and it certainly involves ROS-based ER stress; however, the ER can be or not the main inducer target, as it has been recently speculated by Garg et al. [69]. The well-known inducers of Immunogenic Cell Death, that is, anthracyclines, mitoxantrone, and oxaliplatin [45], primarily localize in the nucleus, inducing apoptosis upon DNA replication and repair damage, and only a fraction of them targets ER, producing ROS-based ER stress, indispensable to elicit immunogenicity during cell death. Similarly, inducers that preferentially localize ER, such as Hypericin, a molecule used in a particular cancer protocol, that is, PDT, are able to induce immunogenic apoptosis upon photo-oxidative ER (phox-ER) stress [70].

In anthracycline-based ecto-CRT translocation, ER stress induction ignites the ER stress response through Phosphorylation of eukaryotic Initiation transcription Factor $2 \alpha$ (eIF$2 \alpha$-P) via serine/threonine kinase PERK (Protein kinase RNA-like Endoplasmic Reticulum Kinase) activation. The consequent apoptosis induction involves caspase 8, Bax and Bak Bcl-2 family members and the ER protein BAP31. CRT translocation on plasma membrane occurs in a SNAREdependent exocytosis, based on a "CRT/Erp57 cotranslocation module" [71].

Conversely, the pathway orchestrating ecto-CRT translocation in phox-ER stress-induced immunogenic apoptosis only requires PERK and $\mathrm{Bax} / \mathrm{Bak}$, but it is independent on eIF- $2 \alpha$-P and caspase- 8 [70].

Moreover, the cotranslocation of CRT with ERp57, that has been described in immunogenic apoptosis, is probably not a universal phenomenon strictly necessary for the immunogenic outcome in cancer therapies. In fact, Garg et al. [70] describe the first ERp57-independent CRT exposure upon phox-ER stress.

Plasma membrane exposed CRT facilitates the engulfment of tumor dead cells by DCs, ensuring their immunogenicity [45]. A series of studies suggests that ecto-CRT exposure occurs in apoptotic anthracyclines, oxaliplatin, UVC, and $\gamma$-radiation induced cancer cells $[45,72]$. These cells subcutaneously injected into syngenic immunocompetent mice boost a strong anticancer immune responses, also protecting against recurrence $[45,72,73]$. Immunogenic response to tumor antigens increases in patients with Acute Myeloid Leukemia (AML) expressing CRT on cell surface of malignant blasts [74]. Moreover, Pekarikova and coworkers [75] demonstrate the presence of high percentage of anticalreticulin antibodies in the serum of patients with gastrointestinal cancer pathology suggesting the cell surface expression of CRT on cancer cells, able to act as a target for B-cell immunogenic response.

The role of anti-CRT antibodies in cancer is enigmatic, since the translocation of CRT onto cell surface and/or its release in extracellular environment elicit an autoimmune reaction also in cancer pathologies [76-78] playing a negative role in antitumor defence [79, 80]. Probably, anti-CRT antibodies can interact with CRT engaging peptides exposed on the tumor cells surface with consequent decrement of cell immunogenicity or they can bind CRT peptides presented by MHC on APC preventing T cell response. The ecto-CRT exposure occurs before the specific morphological, that is, phosphatidylserine (PtdS) exposure on the outer leaflet of plasma membrane, and biochemical, that is, mitochondrial transmembrane potential depolarization, apoptotic signs [71]. The identity of the surface receptor docking ectoCRT is not well known. The ecto-CRT colocalizes with PtdS on plasma membrane cholesterol rich GM-1 gangliosidecontaining rafts [81]. It has been demonstrated that, in phoxER stress, ecto-CRT surface docking does not depend on the correct organization of lipid rafts and occurs via the Lowdensity Receptor-related Protein 1 (LRP1) or CD91 molecule [70].

The extracellular CRT interacts with professional phagocytes plasma membrane CD91 internalization receptor forming a functional complex that drives engulfment of apoptotic died cells by stimulation of Rac-1 in phagocytes [82]. Further, ecto-CRT can also interact with thrombospondin [83], C1q and mannose binding lectin (MBL) [84], ficolin2 and ficolin-3 $[85,86]$, and Surfactant Proteins (SP) A and D [82].

The receptor on DCs surface mediating engulfment by binding CRT-exposed on cancer cells is still obscure. Candidate receptors include scavenger receptor A [87], scavenger receptor class F, member 2 [88], and CD91 [89].

Intriguingly, ecto-CRT has been observed on the plasma membrane of the immune system cells, that is, monocytederived macrophages [90], DCs [91], resting and activated Tcells [92]. For instance, ecto-CRT on DCs plasma membrane interfaces cancer cells and hosts innate immune system by interacting with tumor-associated antigens like NY-ESO-1 [91]. If the presence of CRT on surface of immune cells, that is, macrophages, DCs and T-cells, effectively mediates an "anticancer vaccine effect" is still unclear.

Heat Shock Proteins Family Members. Inducible Heat Shock Proteins (HSPs) are a class of chaperone proteins ensuring the correct folding and subcellular compartments transport of newly synthesized proteins and the refolding or degradation of stress-accumulated misfolded ones [93].

Under stress conditions, intracellularly located HSPs are overexpressed and they can be translocated to plasma membrane surface and/or they can be also released into the extracellular environment. At least two members of HSPs 
family, HSP70 and HSP90, can be expressed at the surface of plasma membrane and the change of cellular localization plays a dual role in cancer [94]. In fact, intracellular, cytoplasmic and organelles-located, overexpressed HSP70 and HSP90 exert a cytoprotective role by apoptosis inhibition [93], augmenting cancer cell survival; conversely, HSPs exposure suppresses tumor by attracting innate immune system cells.

Particularly, HSP70 inhibits (a) the apoptosome complex formation needful for postmitochondrial caspase activation by interacting with Apaf-1 [95]; (b) the caspase-independent apoptosis by blocking AIF translocation from mitochondria to the nucleus [96]; (c) the proapoptotic transcription factor p53 [97] or JNK1 or ERK stress kinases [98]; (d) the Baxdependent release of proapoptotic factor from mitochondria by blocking mitochondrial outer membrane Bax translocation [99]. On the other hand, HSP90 can negatively affect apoptosis by (a) interacting with Apaf-1 and consequently blocking the apoptosome formation [100]; (b) interacting with Akt that, in turn, leads to inactivation of proapoptotic Bad protein and caspase-9, and to activation of NFא B apoptosis inhibition mechanism [101]; (c) inhibiting the action of calpains.

When HSP70 and 90 move from intracellular side to plasma membrane upon stress conditions, for example, oxidative stress, irradiation, serum deprivation, and chemotherapeutics drugs, they elicit a potent immunostimulatory activity. Particularly, in hyperthermia induced surface HSP enriched melanoma [102] and colon carcinoma cells [103], HSP70 and 90 act as DAMPs determining the immunogenicity of dying cancerous cells. HSP70 tightly associates with PtdS on plasma membrane, accelerating apoptosis as reported in PC12 tumor cells [104]. The immunostimulatory effect of ecto-HSP70 and 90 is based on their ability to interact with several APC surface receptors [105], for example, CD91, LOX1, and CD40 [106], and to elicit CD8+ T-cell response by participating in cross-presentation of tumor-derived antigens on MHC class I molecules [107]. This process is very needful in mouse models [108]. Antigen processing and cross-presentation of HSP-linked peptide involve a complex formed by Toll-Like Receptors (TLRs) and CD14 $[109,110]$. TLR4 activates NFאB pathway in DCs that in turn induces the release of proinflammatory cytokines, such as TNF $\alpha$, IL- $1 \beta$, IL-12 and IL-6, and Granulocyte Macrophage Colony-Stimulating Factor (GM-CSF) [109-112]. Besides, HSP70 can promote DCs maturation by upregulating CD86 and CD40 [113] and NKs activation by interacting with various NKs surface localized inhibitory/activating receptors, such as CD94/NKG2A [114] and CD94, respectively, [115].

A number of human and animal tumor cells, that is, colon, pancreas, breast neck and head tumors [102, 103], and acute myeloid leukemia cells [116], express HSPs on their plasma membrane upon heat shock treatment.

The immunogenic potential of HSPs also occurs when they are secreted in the extracellular environment. In fact, high levels of HSP70 and 90 have been detected both in vitro and in vivo. Particularly, in humans, several stress conditions, such as inflammation, bacterial and viral infections, and cancer diseases, lead to HSP70 and 90 presence in the serum of cancer patients. In vitro, the supernatants of the cultured of APCs and tumor cell lines contain members of HSPs family whose release occurs following exogenous stress, that is, proinflammatory cytokines [117].

HSPs surface translocation mechanisms and exposed HSPs derivation, that is, ER, cytosol or both, are still unknown. Also the membrane anchorage and the release process are not completely understood. Several mechanisms have been suggested to explain these phenomena including tumor cell necrosis and apoptosis and, recently, active release from viable tumor cells.

Since cytosolic HSPs do not contain the leader peptides enabling membrane localization, it has been speculated that other proteins possessing transmembrane domain shuttle HSPs from the cytosol to the plasma membrane or that HSPs directly interact with lipid components of plasma membrane. It has been demonstrated, in PC12 cells, that HSP70 associates with PtdS, supporting the hypothesis that the transport of HSP70 from inside the cell to the outer plasma membrane leaflet involves a flip flop mechanism similar to the PtdS one [104].

An active release of HSP70 along with BAG family molecular chaperon regulator 4 (Bag-4) via binding on surface of exosomes, endosome-derived vesicles 30-100 nm sized playing a dual role in cancer pathogenesis [118], has been observed in viable human colon and pancreatic carcinoma cells. Hsp70/Bag-4 surface-positive exosomes elicit migratory and cytolytic activity of NKs [119]. Also 4T1 breast adenocarcinoma and K562 erythroleukemic cells stimulated with IFN- $\gamma$ increase exosomal export of HSP70 inducing IL12 release by DCs [120]. Similarly to tumor cell lines, human peripheral blood mononuclear cells (PBMCs) in both basal and stress-induced (heat shock at 40 or 43 degrees $C$ for $1 \mathrm{~h}$ ) states release HSP70-containing exosomes [121].

Taking into account all the above reported contents, HSPs are reported as DAMPs. Recently, Eden and coworkers [122] argue against the role of HSPs as DAMPs on the basis of the criteria suggested by Kono and Rock in 2008 [123]. These criteria are considered essential in order to classify a particular molecule as DAMP in terms of biological outcomes: a DAMP should be active and a highly purified molecule; its biological effect should not be owing to contamination with microbial molecules; it should be active at concentrations present in pathophysiological status; its selective elimination or inactivation should ideally inhibit dead cells biological activity both in vitro or in vivo assays. HSPs do not satisfy the first two criteria, since, due to their chaperone nature, HSPs engage other molecular structures and they are easily contaminated with microbial products [122].

On the other hand, TLR2 and TLR4, the most credited receptors for HSP60 and HSP70, respectively, are not strictly proinflammatory [124]. Moreover, experiments performed with DCs cultured in the presence of HSPs, both in murine [125] and human models [126, 127], demonstrated no stimulatory effects on DCs activation.

Then, it has been speculated that the HSPs might function as carriers of DAMPs rather than DAMPs, $[116,128]$. 
High Mobility Group Box 1 (HMGB1). The HMGB1 is a $29 \mathrm{kDa}$ nucleus localized and nonhistone chromatin bound protein, also known as amphoterin. It affects different nuclear functions, that is, transcription and nucleoprotein complexes assembly. When it is actively secreted by inflammatory cells or passively released by necrotic cells [129], it acquires immunological potential based on its redox status [130] constituting a crucial step in the activation of APCs [49]. Three types of HMGB proteins exist: HMGB1 ubiquitously expressed [131], and HMGB2 and HMGB3 mostly expressed during embryogenesis and restrictively in adult-stage [132, 133]. Moreover, HMGB1 actively secreted by IL- $1 \beta$, TNF or LPS-activated macrophages and monocytes is molecularly different from that passively released by the necrotic cells, since it is acetylated on several specific lysine residues [134].

Extracellular HMGB1 activates macrophages and DCs $[135,136]$ and burst neutrophil recruitment [137] by binding to a range of receptors, including TLR2, TLR4, and RAGE (Receptor for Advanced Glycation Endproducts) [135].

HMGB1 has several unique roles in cancer. Its expression is very important in lymphoma, melanoma and breast, cervix, colon, liver, lung, and pancreas cancer cells; further, its serum level significantly increases [138].

The HMGB1 release as DAMP is widely demonstrated in necrotic cancer cells [139]. Recently, also apoptotic [41] and autophagic [140] cancer cells might release HMGB1 at some points in their respective execution phases.

The HMGB1-DNA binding dictates the time and the occurrence of release. Since nuclear DNA is released in a time-dependent manner following apoptosis induction [141] and since during apoptosis HMGB1-DNA binding increases, apoptotic cells can release DNA as well as HMGB1 during later stages, for example, secondary necrosis [130, 142, 143]. In contrast to inflammatory response initiated by necrotic cells [139], ROS produced and HMGB1 released by apoptotic cells promote tolerance [130].

Recently Liu and coworkers [144] found that HMGB1 release after vincristine (VCR), cytosine arabinoside, arsenic trioxide adriamycin (ADM) chemotherapy treatment is a critical regulator of autophagy in HL-60 and Jurkat leukemia cells and a potential drug target for therapeutic intervention. In fact, HMGB1 contributes to chemotherapy resistance through autophagy regulation [145]. It has been demonstrated that leukemia cells sensitivity to chemotherapeutic agents increases by inhibiting HMGB1 release; conversely, leukemia cells resist to cell death by overexpressing HMGB1; finally, pretreatment with exogenous HMGB1 increases leukemia cells drug resistance [145]. Moreover, HMGB1mediated autophagy depends on Beclin-1 regulation carried out by HMGB1 itself and it requires PI3KC3-MEK-ERK pathway. In fact, Liu et al. [144] found that HMGB1 increases Beclin 1/class III phosphatidylinositol 3-kinase (PI3KC3) and suppresses Beclin 1/Bcl-2 interaction, promoting vesicle nucleation. HMGB1 also contributes to phagophore membrane elongation and autophagosome formation by promoting Atg12-Atg5-Atg16 complex formation and by enhancing the accumulation of the Atg12-Atg5-Atg16 complex with LC3.
Finally, the redox state controls HMGBl's function in promotion of autophagy. In particular, reducible HMGB1 decreases cell injury/death in cancer cells by interfering with Beclin 1, whereas oxidized HMGB1 enhances cell injury/death in response to anticancer agents [146].

End-Stage Degradation Products. Upon loss of membrane integrity during primary or secondary necrosis, intracellular substances normally retained within cells are released. These end-stage degradation products, including uric acid, RNA, genomic double-stranded DNA, nucleotides (ATP) and nucleosides (adenosine), exert immunostimulatory effects on macrophages and DCs $[50,147,148]$. The uric acid is the end product of purine metabolism in uricotelic mammals, identified as a major alarmin released by injured cells since it elicits inflammation by enhancing CD8+ [149] and CD4+ [150] T cell responses towards particulate antigens. Plasma membrane collapse leads to release of (1) RNA molecules, interacting with TLR3 on DCs [51]; (2) double-stranded DNA, stimulating both macrophages and DCs [50]; (3) nucleotides, triggering maturation of DCs [147] through activation of the NFKB signaling [151]. Parallel to passive release, ATP can be liberated into the extracellular space by voltage-gated hemichannels such as pannexin 1 or connexin [152] and/or vesicular exocytosis [153].

Inflammatory Cytokines. Necrotic cells can also elicit an inflammatory response by active or passive secretion of inflammatory cytokines, that is, IL- $1 \alpha$ e IL-6. In particular, Eigenbrod et al. [154] demonstrated that IL- $1 \alpha$ is passively released by necrotic cells and it induces, in peritoneum mesothelial cells, secretion of CXCL1, leading to neutrophilic inflammation. Conversely, necrotic cells actively release proinflammatory cytokine IL- 6 by upregulating $\mathrm{NF} \kappa \mathrm{B}$ and p38MAPK [155]. End-stage degradation products modulate their recognition by the immune system cells via the pentraxins, a family of innate immunity receptors [156].

4.2. ICD: Immunogenic Signals Delivery Spatiotemporal Pattern. ICD can be triggered by a panoply of anticancer stimuli, including Photodynamic Therapy, anthracyclineand oxaliplatin-based chemotherapy, and $\gamma$-radiotherapy. The spatiotemporal sequence responsible or not for the stimulation of the immune system, dictating the success of cancer therapy, includes three phases: decision phase, processing phase, and effector phase [43].

In the decision phase, CRT early (within few hours) translocates on plasma membrane of dying tumor cells colocalizing in patches with PtdS in concomitance with ER stress response. CRT acts as an "eat me signal", driving the engulfment of dying cancer cells and in parallel the uptake of tumor antigens by DCs [45]. The uptake, via a CRT-dependent manner, is ensured by loss/redistribution of CD47, a "don't eat me signal" that avoids the accidental phagocytosis of viable cells [157], occurring within 30 minutes after the induction of apoptosis [81] and hence displaying a pattern similar to CRT translocation. Late exposure on cell surface of HSP70 and 90 cooperates in the tumor antigen chaperoning 
and in the adhesion of tumor cells to DCs, respectively, $[106,158]$.

However, the DC-mediated uptake of tumor antigens is not sufficient to ignite immune response. In fact, the fusion antigen-containing phagosomes with lysosomes causes the destruction of antigens [159], that can be inhibited by recognition of DAMPs by TLRs localized on DCs surface [160]. Thus, other signals are required during processing phase to stimulate antigen processing. Among TLR4 ligands, the release of HMGB1, occurring within 18 hours after ICD induction, plays a key role. It has been suggested that the physical interplay between TLR4 and HMGB1 [49] triggers an immunogenic signal operating downstream of the DCmediated antigen uptake that enables the optimal presentation of tumor antigens to T lymphocytes [73]. In addition, the antitumor immune response is controlled by NLR family, pyrin domain containing 3 (NLRP3) inflammasome [161]. ATP, released into the extracellular space during cellular stress, is the most abundant factor activating NLRP3 [162], that is essential for processing pro-IL- $1 \beta$ and secretion of IL$1 \beta$ [163], that, in turn, primes CD4+ and CD8+ lymphocytes and elicits the antitumor response. ATP also functions as a "find me signal" promoting monocytes recruitment and activation [164].

In effector phase, matured and activated DCs elicit an IFN- $\gamma$-polarized T cell response, essential for efficient antitumor immunity [45, 49, 161].

In Figure 1, we represent the temporal exposure and/or release of DAMPs and the relative response of immune cells in in vitro conditions.

\section{The Response of Immune System to Photodynamic Treatment}

The ability of PDT to induce activation of the immune system and specific antitumor immunity is a well-known phenomenon, recently reviewed in Pizova et al. [165]. Indeed, the ignition of anticancer immunity is as important as tumor cell death in designing an optimal cancer therapy $[12,40$, 166]. In terms of ICD, various DAMPs can mediate antitumor immunity in PDT and a broad spectrum of photosensitizers localizing different subcellular organelles, especially ER, is very important in ICD triggering upon PDT [167].

5.1. How PDT Elicit Antitumor Immunity. Three mechanisms interplay to reduce and/or eradicate tumors after PDT: cancer cell death via ROS generation, ischemia of tumor area via destruction of tumor-associated vasculature depleting cancer cells of oxygen and nutrients, recruitment of inflammatory and immune mediators contributing to tumor destruction, and recognition of cancer cells via leukocytes invasion [168].

The triggered inflammatory responses are fundamental to achieve long-term tumor control [169].

The innate immunity against cancer is a step-bystep process involving initiation of inflammation, cytokine release, neutrophil infiltration of tumor site and neutrophilia and, finally, complement activation. On the other hand, acute inflammation can supply bioactive molecules to the tumor microenvironment, including growth factors that sustain proliferative signaling, survival factors that limit cell death, proangiogenic factors, extracellular matrix-modifying enzymes that facilitate angiogenesis, invasion, and metastasis, and inductive signals that support tumorigenesis [170-173]. Antitumor effect of cancer PDT involves both innate and adaptive immune system.

PDT alters the tumor microenvironment by causing oxidative stress which triggers a vast array of signal pathways through TLRs, stimulating inflammation by expression of HSPs, NF $\kappa$ B and AP-1 [169]. The increased activity of these factors has been reported in several cancer cell lines photodynamically treated with different PSs. For example, NF $\kappa B$ activation has been observed in L1210 mouse leukemia cells after Photofrin-PDT [174], in lymphocytes or monocytes infected with HIV-1 after proflavine-PDT [175], in human colon carcinoma cells phototreated with pyropheophorbidea methyl ester (PPME) [176], and in human HL-60 cells after PDT with benzoporphyrin-derivative-(BPD-) verterporfin [177]. Similarly, AP-1 activation occurs in cervical carcinoma HeLa cells [178] and in epithelial PAM 212 cells [179] photosensitized with Photofrin.

$\mathrm{NF} \kappa \mathrm{B}$ and $\mathrm{AP}-1$ activation causes release by macrophages of different immunoregulatory and proinflammatory proteins, such as interleukins (IL- $1 \alpha,-1 \beta,-2,-6,-8,-11,-12$, -15), tumor necrosis factor (TNF), chemokines (inflammatory protein IP-10, keratinocytes-derived chemokines KC, Macrophage Inflammatory Proteins MIP- $1 \alpha$ and $\beta$, MIP2, eotaxin, Methyl-accepting Chemotaxis Protein MCP1, Regulated on Activation Normal $\mathrm{T}$ cell Expressed and Secreted, RANTES), and interferons (IFN- $\alpha$ and $\beta$ ) (reviewed in [169]).

Other cell types eliciting innate immunity in PDT are neutrophils. They play a fundamental role both in the direct killing of tumor cells and in the activation of other immune cells. Moreover, they are also a source of proinflammatory mediators [180]. Neutrophils do not only accumulate in PDTtreated tumors, but they are also present in the blood of the host (so-called neutrophilia) [181]. Cecic et al. [182] reported that, in mammary carcinoma EMT6 tumors, PhotofrinPDT induces in the host mice a significant increment of neutrophils in blood persisting for at least 10 hours after treatment. Also Gollnick et al., [34] report that 2[1-hexyloxyethyl]-2-devinyl pyropheophorbide- $\alpha$ (HPPH)mediated-PDT causes neutrophil migration into the tumor area as well as Krosl and colleagues [183] report a 200fold rise in neutrophils in the cellular infiltrate in SCCVII tumor treated with Photofrin-PDT. Finally, treatment of rat rabdomyosarcoma tumors with 5-aminolevulinic acid (5ALA)-PDT induces a blood neutrophils increase during the first few days after illumination [184].

Thus, PDT prompts a powerful acute inflammation leading to activation of complement cascade likely by the alternative pathway $[180,182,185,186]$. In particular, in vitro studies indicate that PDT induces fixation of complement C3 protein to tumor cells [187] that, in turn, marks the cells to be destructed by the innate immune system [188190]. The complement system can directly promote T-cell 


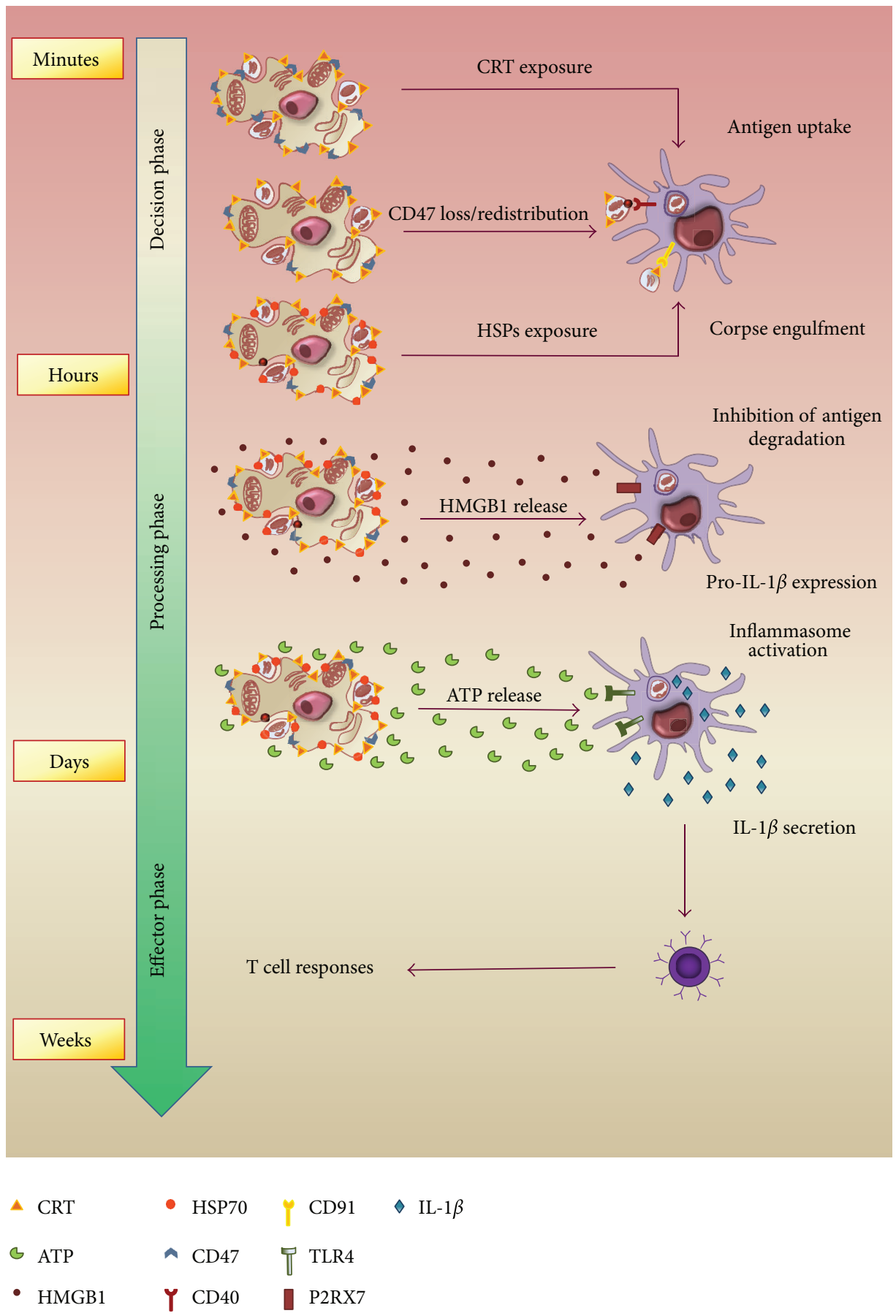

FIGURE 1: Spatiotemporal immunogenic signals delivery pattern. Decision phase, processing phase, and effector phase represent the spatiotemporal sequence determining the activation of immune system in in vitro conditions.

mediate response, playing a role in the adaptive immunity [191] carried out by antigen-specific B and T cells.

The growth inhibition of murine EMT6 tumors dependent on the presence of CD8+ T cells has been demonstrated after Photofrin-PDT by Kabingu and coworkers [192]. Preise et al. [38], by transferring CD8+ and CD4+ T cells from mice survived to cancer 3 months after vascular targeted PDT with bacteriochlorophyll derivative WST11, found that the transferred mice are protected from subsequent challenge with viable cancer cells. Similar results have been obtained in human studies. For example, Thong et al. [193] demonstrated increased CD8+ T cell infiltration into multifocal angiosarcoma of the head and neck carcinoma area phototreated with Fotolon, a PS comprising 1:1 chlorin e6 and polyvinylpyrrolidone. Photodynamic treatment with Photofrin or 5-ALA in patients with basal cell carcinoma 
provides an enhanced recognition of MHC-I-antigen complexes by immune cells and the activation of tumor specific CD8+ T cells [194].

The activity of CD8+ cells upon PDT is correlated to the presence of tumor antigens eliciting a potent antitumor effect. In fact, Mroz and coworkers [195], demonstrated that BPD-PDT can induce a strong antigen specific immune response capable to incite the memory immunity enabling $\mathrm{BALB} / \mathrm{c}$ mice to reject a tumor rechallenge obtained with the same antigen positive tumor from which they were cured. The importance of tumor antigen presence is confirmed by the observation that BPD-PDT low level distant metastasis destruction correlates with a loss of tumor antigen expression.

It is worth mentioning that, certain PDT regimens systematically suppress immune reactivity [169]. Cutaneous Photofrin-PDT induces elevated levels of systemic IL-10, correlating to a prolonged suppression of contact ipersensitivity (CHS) reaction of at least 28 days following treatment. Since the major effector cell in CHS is the IFN- $\gamma$ secreting CD8+ cell and IL-10 suppresses cell-mediated immune response via inhibition of CD4+ cells activation, it is possible that PDT negatively influences the CD4+ or CD8+ development. Moreover, the inhibition of CD4+ or CD8+ activity can be caused by induction of systemic IL-4 [196]. Yusuf et al. [197] demonstrated that silicon phtalocyanine (Pc4)-PDT causes immunosuppression in cancer ill mice by involving of CD4+ and CD8+ T cells. Moreover, immunosuppression can be adoptively transferred with spleen cells from Pc4PDT treated donor mice to syngenic naive recipients and it is primarily mediated by $\mathrm{T}$ cells, although macrophages were also found to partecipate. Among CD4+ cells, a special population that functionally suppresses an immune response is Tregs. They mediate their immunosuppressive effects by multiple pathways [198]. Particularly, Tregs express TGF$\beta$, an immunosuppressive cytokine [199] participating in further proliferation of Tregs [200], and suppress DCs activation [201]. Castano and collegues [202] observed that Tregs can be depleted by cyclophosphamide (CY) that, in combination with $\mathrm{PBD}-\mathrm{PDT}$, leads a long-term J774 reticulum cell sarcoma cure and resistance to tumor rechallenge.

\subsection{Involvement of ICD in Photodynamic Cancer Therapy.}

The link between PDT and HSPs, and especially HSP70, the best characterized DAMPs in PDT, [203] is already known as well as the immunogenicity of PDT treatment and its ability to elicit an antitumor immunity [204].

PDT is able to trigger the main types of cell death, that is, apoptosis, autophagic cell death, and necrosis [26]. It is interesting to understand if there exists a relation between PDT-induced cell death and DAMPs and between DAMPs and ICD. In case of necrosis, DAMPs spectrum does not change relatively to agents inducing them, including PDT. For example, the release of HMGB1 has been demonstrated both in serum of Photofrin-treated mice with subcutaneous Lewis Lung Carcinoma (LLC) and in LLC Photofrin-treated cells [205]. On the other hand, HMGB1 has been reported to be the only DAMP involved in autophagy [144-146], but nothing is known about the DAMPs associated with autophagic cell death induced by photodynamic treatment. Moreover, PDT-induced apoptotic cells have been predominantly associated with HSPs [204] and only recently it has been suggested the involvement of CRT and ATP in apoptotic cell death upon photodynamic sensitization [70].

Interestingly, we found, for the first time, that Rose Bengale Acetate (RBAc) is able to induce the release and translocation of HSP70 and 90 and the exposure of CRT on plasma membrane of both apoptotic and autophagic RBAcPDT induced HeLa cells (unpublished data). However, it is still under investigation the involvement of these DAMPs in RBAc-PDT induced immunogenicity.

The DAMPs spectrum observed in PDT is reported in Figure 2.

In the following section, the link between DAMPsassociated PDT and their involvement in the elicitation of immune cells have been discussed in detail.

Interplay between DAMPs Involved in PDT-Induced Cell Death and Immunogenicity. The best characterized DAMPs involved in PDT-triggered cell death able to confer immunogenicity are HSPs proteins and especially HSP70, as described for squamous cells carcinoma SCCVII [203], murine mammary tumor cells C127 [206] during Photofrin-PDT, EMT6 cells during meso-tetrahydroxyphenyl chlorin (mTHPS, Foscan)PDT [207] and glioblastoma cell lines U87 and U251 during 5-ALA-PDT [208].

It has been observed that almost instantaneously HSP70 can be translocated onto the outer leaflet of plasma membrane of SCCVII cells apoptotically committed with Photofrin-based PDT. The authors reported that several other HSPs, that is, HSP60 and Glucose regulated Protein 94 (GRP94) are also exposed at the surface of tumor SCCVII cells. A fraction of HSP70 is promptly (within 1 hour) released by cells after high treatment doses, whereas lower PDT doses induce a HSP70 release at later time intervals, suggesting that the release is a consequence of membrane permeabilization upon necrosis. The induction of cell surface expression and release of HSPs stimulate macrophages coincubated with PDT-treated SCCVII cells to produce TNF- $\alpha$. This study also suggests that DAMPs exposed onto the surface in response to PDT stress based on in vitro or in vivo settings, are probably related to tumor microenvironment. In fact, when authors induce SCCVII tumor in mice, they observe that cancer cells expose GRP78 rather than HSP60 and GRP94 [203]. Moreover, ecto-HSP70 participates in the opsonization of cancer cells by C3 complement protein [209]. Similarly, Zhou and coworkers [206] demonstrated that HSP70 secreted and released by $\mathrm{C} 127$ cells induced to apoptosis by Photofrin-PDT orchestrates an immunological regulatory mechanism towards murine Raw 264.7 macrophages. In fact, macrophages incubated with apoptotic cells as well as necrotic tumor cells showed a high level of TNF- $\alpha$ secretion. Also EMT6 cells photosensitized with Foscan expose and release HSP70 resulting in longterm tumor growth control [207]. In 5-ALA spheroids of 


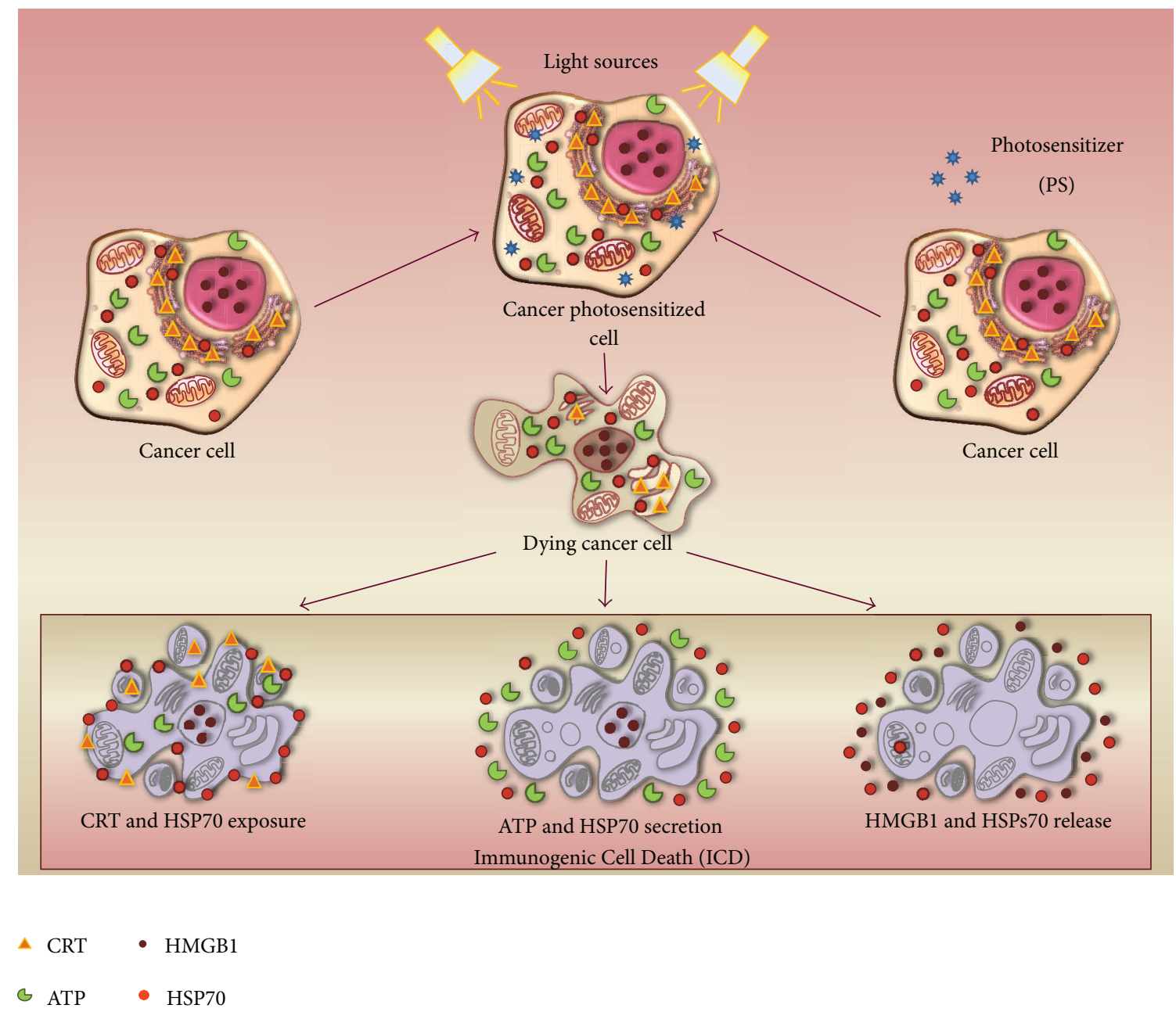

FIgURE 2: Molecular mechanisms of PDT-induced Immunogenic Cell Death (ICD). The three main processes characterizing the ICD are the preapoptotic cell surface exposure of calreticulin (CRT) and HSP70, the secretion of ATP and HSP70, and the postapoptotic release of HMGB1 and HSP70.

glioblastoma cell lines U87 and U251, HSP70 is expressed on the surface of cancerous cells and induces both attraction and maturation of DCs and antigen uptake by upregulation of CD83 and costimulatory molecules as well as increasing T-cell stimulatory activity of DCs [208].

Recently, experiments performed in the Agostinis laboratory reveal that the CRT exposure and ATP secretion during PDT elicit ICD, adding Hypericin-(Hyp-) based PDT to the list of ICD inducers [70, 210].

Hyp-PDT causes, soon after 30 minutes after irradiation, the precocious exposure on surface of T24 human bladder carcinoma and colon carcinoma CT26 cells of both CRT and HSP70 [210]; moreover, T24 cells secrete ATP in response to Hyp-PDT [70]. Ecto-CRT exposure depends on the PDT dose, both in PS concentration and in light fluence; surprisingly, conversely to the literature data reporting cotranslocation of ERp57 and CRT on plasma membrane, after HypPDT, T24 cells expose CRT in the absence of ERp57 and it does not require eIF2 $\alpha$ phosphorylation, caspase 8 activity, and increased cytosolic $\mathrm{Ca}^{2+}$ concentration [70, 210]. In terms of immune cells ignition, only ecto-CRT influences phagocytosis of T24 and Ct26 dead cells. In fact, T24 cells succumbing to Hyp-PDT were engulfed by murine Mf4/4 macrophages and human DCs [70]; similarly, CT26 HypPDT photokilled cells were preferentially phagocytosed by JAWSII murine dendritic cells [210]. Moreover, CT26 HypPDT photokilled cells immunized syngenic BALB/c mice against a recidive in the presence of living CT26 cancer cells [70]. DCs cultured in the presence of Hyp-PDT treated T24 cells produce high levels of Nitric Oxide (NO) and IL- $1 \beta$, but they do not secrete the anti-inflammatory IL10 [70]. Since IL- $1 \beta$ is involved in polarization of IFN$\gamma$ - producing antineoplastic CD8+ T cells [211], Garg et al. [70] found the antitumor immune response elicited by Hyp-PDT. The authors [70] also suggest the processes and molecules sustaining CRT exposure, that is, ROS production, 
class I phosphoinositide-3-kinase (PI3K) activation, actin cytoskeleton, ER-to-Golgi anterograde transport, PERK, Bax and Bak proapoptotic proteins and CRT cell surface receptor CD91, and ATP release, that is, ER-to-Golgi anterograde transport, PI3K and PERK.

\section{Concluding Remarks}

The knowledge of DAMPs involved in cell death inducing cancer settings could help in the prompt choice of the better therapeutic design for a particular cancer condition. In fact, cancer therapies associated with DAMPs expression, in term of both exposure on plasma membrane and release on extracellular environment, have been shown to be able to fuse efficient cell death induction and activation of antitumor immune response. DAMPs can be also exploited as tool to mark disease's stage and to identify the extent of inflammation associated with the disease. Further, they can be used to prepare highly immunogenic vaccines. Due to its uniqueness to efficiently induce cell demise, antitumor effect by involving both innate and adaptive immune system and DAMPs expression, PDT is very promising to optimize cancer protocol. In fact, by inducing ICD, PDT could be capable to counteract cancer recurrence by instructing immune system.

In this context, it is a priority for the future oncology practice to clarify the molecular mechanisms associated with the immune response triggered by immunogenic tumor cell death.

\section{References}

[1] D. Hanahan and R. A. Weinberg, "Hallmarks of cancer: the next generation," Cell, vol. 144, no. 5, pp. 646-674, 2011.

[2] M. A. Blasco, "Telomeres and human disease: ageing, cancer and beyond," Nature Reviews Genetics, vol. 6, no. 8, pp. 611-622, 2005.

[3] J. E. Talmadge and I. J. Fidler, "AACR centennial series: the biology of cancer metastasis: historical perspective," Cancer Research, vol. 70, no. 14, pp. 5649-5669, 2010.

[4] F. Cavallo, C. De Giovanni, P. Nanni, G. Forni, and P. L. Lollini, "2011: the immune hallmarks of cancer," Cancer Immunology, Immunotherapy, vol. 60, no. 3, pp. 319-326, 2011.

[5] H. Norell, M. Carlsten, T. Ohlum et al., "Frequent loss of HLAA2 expression in metastasizing ovarian carcinomas associated with genomic haplotype loss and HLA-A2-restricted HER2/neu-specific immunity," Cancer Research, vol. 66, no. 12, pp. 6387-6394, 2006.

[6] B. Seliger, "Molecular mechanisms of MHC class I abnormalities and APM components in human tumors," Cancer Immunology, Immunotherapy, vol. 57, no. 11, pp. 1719-1726, 2008.

[7] F. M. Burnet, "The concept of immunological surveillance," Progress in Experimental Tumor Research, vol. 13, pp. 1-27, 1970.

[8] G. P. Dunn, L. J. Old, and R. D. Schreiber, "The three Es of cancer immunoediting," Annual Review of Immunology, vol. 22, pp. 329-360, 2004.
[9] D. Chaudhuri, R. Suriano, A. Mittelman, and R. K. Tiwari, "Targeting the immune system in cancer," Current Pharmaceutical Biotechnology, vol. 10, no. 2, pp. 166-184, 2009.

[10] O. Kepp, A. Tesniere, F. Schlemmer et al., "Immunogenic cell death modalities and their impact on cancer treatment," Apoptosis, vol. 14, no. 4, pp. 364-375, 2009.

[11] L. Zitvogel, O. Kepp, and G. Kroemer, "Decoding cell death signals in inflammation and immunity," Cell, vol. 140, no. 6, pp. 798-804, 2010.

[12] L. Galluzzi, I. Vitale, J. M. Abrams et al., "Molecular definitions of cell death subroutines: recommendations of the Nomenclature Committee on Cell Death 2012," Cell Death and Differentiation, vol. 19, no. 1, pp. 107-120, 2012.

[13] L. Zitvogel, N. Casares, M. O. Péquignot, N. Chaput, M. L. Albert, and G. Kroemer, "Immune response against dying tumor cells," Advances in Immunology, vol. 84, pp. 131-179, 2004.

[14] L. Zitvogel, O. Kepp, L. Senovilla, L. Menger, N. Chaput, and G. Kroemer, "Immunogenic tumor cell death for optimal anticancer therapy: the calreticulin exposure pathway," Clinical Cancer Research, vol. 16, no. 12, pp. 3100-3104, 2010.

[15] A. D. Garg, D. Nowis, J. Golab, and P. Agostinis, "Photodynamic therapy: illuminating the road from cell death towards anti-tumour immunity," Apoptosis, vol. 15, no. 9, pp. 1050-1071, 2010.

[16] P. Agostinis, A. Vantieghem, W. Merlevede, and P. A. M. de Witte, "Hypericin in cancer treatment: more light on the way," International Journal of Biochemistry and Cell Biology, vol. 34, no. 3, pp. 221-241, 2002.

[17] P. Agostinis, E. Buytaert, H. Breyssens, and N. Hendrickx, "Regulatory pathways in photodynamic therapy induced apoptosis," Photochemical \& Photobiological Sciences, vol. 3, no. 8, pp. 721-729, 2004.

[18] E. Buytaert, M. Dewaele, and P. Agostinis, "Molecular effectors of multiple cell death pathways initiated by photodynamic therapy," Biochimica et Biophysica Acta, vol. 1776, no. 1, pp. 86-107, 2007.

[19] A. P. Castano, T. N. Demidova, and M. R. Hamblin, "Mechanisms in photodynamic therapy: part one-photosensitizers, photochemistry and cellular localization," Photodiagnosis and Photodynamic Therapy, vol. 1, no. 4, pp. 279-293, 2004.

[20] B. W. Henderson and T. J. Dougherty, "How does photodynamic therapy work?" Photochemistry and Photobiology, vol. 55, no. 1, pp. 145-157, 1992.

[21] L. Brancaleon and H. Moseley, "Laser and non-laser light sources for photodynamic therapy," Lasers in Medical Science, vol. 17, no. 3, pp. 173-186, 2002.

[22] K. Plaetzer, B. Krammer, J. Berlanda, F. Berr, and T. Kiesslich, "Photophysics and photochemistry of photodynamic therapy: fundamental aspects," Lasers in Medical Science, vol. 24, no. 2, pp. 259-268, 2009.

[23] A. Greer, "Christopher Foote's discovery of the role of singlet oxygen $\left[{ }^{1} \mathrm{O}_{2}\left({ }^{1} \Delta_{g}\right)\right]$ in photosensitized oxidation reactions," Accounts of Chemical Research, vol. 39, no. 11, pp. 797-804, 2006.

[24] A. P. Castano, P. Mroz, and M. R. Hamblin, "Photodynamic therapy and anti-tumour immunity," Nature Reviews Cancer, vol. 6, no. 7, pp. 535-545, 2006.

[25] M. Korbelik, "PDT-associated host response and its role in the therapy outcome," Lasers in Surgery and Medicine, vol. 38, no. 5, pp. 500-508, 2006. 
[26] P. Mroz, A. Yaroslavsky, G. B. Kharkwal, and M. R. Hamblin, "Cell death pathways in photodynamic therapy of cancer," Cancers, vol. 3, no. 2, pp. 2516-2539, 2011.

[27] A. Burlacu, "Regulation of apoptosis by Bcl-2 family proteins," Journal of Cellular and Molecular Medicine, vol. 7, no. 3, pp. 249-257, 2003.

[28] N. L. Oleinick, R. L. Morris, and I. Belichenko, “The role of apoptosis in response to photodynamic therapy: what, where, why, and how," Photochemical \& Photobiological Sciences, vol. 1, no. 1, pp. 1-21, 2002.

[29] D. Kessel and N. L. Oleinick, "Initiation of autophagy by photodynamic therapy," Methods in Enzymology, vol. 453, pp. $1-16,2009$.

[30] V. Inguscio, E. Panzarini, and L. Dini, "Autophagy contributes to the death/survival balance in cancer photodynamic therapy," Cells, vol. 1, pp. 464-491, 2012.

[31] R. Scherz-Shouval and Z. Elazar, "ROS, mitochondria and the regulation of autophagy," Trends in Cell Biology, vol. 17, no. 9, pp. 422-427, 2007.

[32] E. Panzarini, V. Inguscio, and L. Dini, “Timing the multiple cell death pathways initiated by Rose Bengal acetate photodynamic therapy," Cell Death and Disease, vol. 2, no. 6, article e169, 2011.

[33] E. Panzarini, V. Inguscio, and L. Dini, "Overview of cell death mechanisms induced by Rose Bengal acetate-photodynamic therapy," International Journal of Photoenergy, vol. 2011, Article ID 713726, 11 pages, 2011.

[34] S. O. Gollnick, L. Vaughan, and B. W. Henderson, "Generation of effective antitumor vaccines using photodynamic therapy," Cancer Research, vol. 62, no. 6, pp. 1604-1608, 2002.

[35] C. M. Brackett and S. O. Gollnick, "Photodynamic therapy enhancement of anti-tumor immunity," Photochemical \& Photobiological Sciences, vol. 10, no. 5, pp. 649-652, 2011.

[36] S. O. Gollnick, S. S. Evans, H. Baumann et al., "Role of cytokines in photodynamic therapy-induced local and systemic inflammation," British Journal of Cancer, vol. 88, no. 11, pp. 1772-1779, 2003.

[37] P. C. Kousis, B. W. Henderson, P. G. Maier, and S. O. Gollnick, "Photodynamic therapy enhancement of antitumor immunity is regulated by neutrophils," Cancer Research, vol. 67, no. 21, pp. 10501-10510, 2007.

[38] D. Preise, R. Oren, I. Glinert et al., "Systemic antitumor protection by vascular-targeted photodynamic therapy involves cellular and humoral immunity," Cancer Immunology, Immunotherapy, vol. 58, no. 1, pp. 71-84, 2009.

[39] A. Jalili, M. Makowski, T. Świtaj et al., "Effective photoimmunotherapy of murine colon carcinoma induced by the combination of photodynamic therapy and dendritic cells," Clinical Cancer Research, vol. 10, no. 13, pp. 4498-4508, 2004.

[40] L. Zitvogel, L. Apetoh, F. Ghiringhelli, and G. Kroemer, "Immunological aspects of cancer chemotherapy," Nature Reviews Immunology, vol. 8, no. 1, pp. 59-73, 2008.

[41] D. R. Green, T. Ferguson, L. Zitvogel, and G. Kroemer, "Immunogenic and tolerogenic cell death," Nature Reviews Immunology, vol. 9, no. 5, pp. 353-363, 2009.

[42] A. Tesniere, L. Apetoh, F. Ghiringhelli et al., "Immunogenic cancer cell death: a key-lock paradigm," Current Opinion in Immunology, vol. 20, no. 5, pp. 504-511, 2008.

[43] O. Kepp, L. Galluzzi, I. Martins et al., "Molecular determinants of immunogenic cell death elicited by anticancer chemotherapy," Cancer and Metastasis Reviews, vol. 30, no. 1, pp. 61-69, 2011.
[44] A. Rubartelli and M. T. Lotze, "Inside, outside, upside down: damage-associated molecular-pattern molecules (DAMPs) and redox," Trends in Immunology, vol. 28, no. 10, pp. 429-436, 2007.

[45] M. Obeid, A. Tesniere, F. Ghiringhelli et al., "Calreticulin exposure dictates the immunogenicity of cancer cell death," Nature Medicine, vol. 13, no. 1, pp. 54-61, 2007.

[46] R. Spisek, A. Charalambous, A. Mazumder, D. H. Vesole, S. Jagannath, and M. V. Dhodapkar, "Bortezomib enhances dendritic cell (DC)-mediated induction of immunity to human myeloma via exposure of cell surface heat shock protein 90 on dying tumor cells: therapeutic implications," Blood, vol. 109, no. 11, pp. 4839-4845, 2007.

[47] A. Mukhopadhaya, J. Mendecki, X. Dong et al., "Localized hyperthermia combined with intratumoral dendritic cells induces systemic antitumor immunity," Cancer Research, vol. 67, no. 16, pp. 7798-7806, 2007.

[48] C. Didelot, D. Lanneau, M. Brunet et al., "Anti-cancer therapeutic approaches based on intracellular and extracellular heat shock proteins," Current Medicinal Chemistry, vol. 14, no. 27, pp. 2839-2847, 2007.

[49] L. Apetoh, F. Ghiringhelli, A. Tesniere et al., "The interaction between HMGB1 and TLR4 dictates the outcome of anticancer chemotherapy and radiotherapy," Immunological Reviews, vol. 220, no. 1, pp. 47-59, 2007.

[50] K. J. Ishii, K. Suzuki, C. Coban et al., "Genomic DNA released by dying cells induces the maturation of APCs," The Journal of Immunology, vol. 167, no. 5, pp. 2602-2607, 2001.

[51] K. Karikó, H. Ni, J. Capodici, M. Lamphier, and D. Weissman, "mRNA is an endogenous ligand for toll-like receptor 3," The Journal of Biological Chemistry, vol. 279, no. 13, pp. 12542-12550, 2004.

[52] H. Kono, C. J. Chen, F. Ontiveros, and K. L. Rock, "Uric acid promotes an acute inflammatory response to sterile cell death in mice," The Journal of Clinical Investigation, vol. 120, no. 6, pp. 1939-1949, 2010.

[53] D. Foell, H. Wittkowski, T. Vogl, and J. Roth, "S100 proteins expressed in phagocytes: a novel group of damage-associated molecular pattern molecules," Journal of Leukocyte Biology, vol. 81, no. 1, pp. 28-37, 2007.

[54] N. M. Luheshi, J. A. Giles, G. Lopez-Castejon, and D. Brough, "Sphingosine regulates the NLRP3-inflammasome and IL- $1 \beta$ release from macrophages," European The Journal of Immunology, vol. 42, no. 3, pp. 716-725, 2012.

[55] G. Srikrishna and H. H. Freeze, "Endogenous damageassociated molecular pattern molecules at the crossroads of inflammation and cancer," Neoplasia, vol. 11, no. 7, pp. 615-628, 2009.

[56] K. L. Rock and H. Kono, "The inflammatory response to cell death," Annual Review of Pathology, vol. 3, pp. 99-126, 2008.

[57] C. S. Calfee and M. A. Matthay, "Clinical immunology: culprits with evolutionary ties," Nature, vol. 464, no. 7285, pp. 41-42, 2010.

[58] S. S. Iyer, W. P. Pulskens, J. J. Sadler et al., "Necrotic cells trigger a sterile inflammatory response through the Nlrp3 inflammasome," Proceedings of the National Academy of Sciences of the United States of America, vol. 106, no. 48, pp. 20388-20393, 2009.

[59] L. Schaefer, "Extracellular matrix molecules: endogenous danger signals as new drug targets in kidney diseases," Current Opinion in Pharmacology, vol. 10, no. 2, pp. 185-190, 2010. 
[60] T. E. Ichim, Z. Zhong, S. Kaushal et al., "Exosomes as a tumor immune escape mechanism: possible therapeutic implications," Journal of Translational Medicine, vol. 6, article 37, 2008.

[61] L. Zitvogel, A. Tesniere, and G. Kroemer, "Cancer despite immunosurveillance: immunoselection and immunosubversion," Nature Reviews Immunology, vol. 6, no. 10, pp. 715-727, 2006.

[62] M. Michalak, J. Groenendyk, E. Szabo, L. I. Gold, and M. Opas, "Calreticulin, a multi-process calcium-buffering chaperone of the endoplasmic reticulum," Biochemical Journal, vol. 417, no. 3, pp. 651-666, 2009.

[63] J. Groenendyk, J. Lynch, and M. Michalak, "Calreticulin, $\mathrm{Ca}^{2+}$, and calcineurin-signaling from the endoplasmic reticulum," Molecules and Cells, vol. 17, no. 3, pp. 383-389, 2004.

[64] B. Gao, R. Adhikari, M. Howarth et al., "Assembly and antigenpresenting function of MHC class I molecules in cells lacking the ER chaperone calreticulin," Immunity, vol. 16, no. 1, pp. 99-109, 2002.

[65] J. M. Holaska, B. E. Black, F. Rastinejad, and B. M. Paschal, "Ca ${ }^{2+}$-dependent nuclear export mediated by calreticulin," Molecular and Cellular Biology, vol. 22, no. 17, pp. 6286-6297, 2002.

[66] N. Mesaeli and C. Phillipson, "Impaired p53 expression, function, and nuclear localization in calreticullum-deficient cells," Molecular Biology of the Cell, vol. 15, no. 4, pp. 1862-1870, 2004.

[67] K. L. Shaffer, A. Sharma, E. L. Snapp, and R. S. Hegde, "Regulation of protein compartmentalization expands the diversity of protein function," Developmental Cell, vol. 9, no. 4, pp. 545-554, 2005.

[68] W. A. Wang, J. Groenendyk, and M. Michalak, "Calreticulin signaling in health and disease," The International Journal of Biochemistry \& Cell Biology, vol. 44, no. 6, pp. 842-846, 2012.

[69] A. D. Garg, D. V. Krysko, P. Vandenabeele, and P. Agostinis, "The emergence of phox-ER stress induced immunogenic apoptosis," Oncoimmunology, vol. 1, no. 5, pp. 786-788, 2012.

[70] A. D. Garg, D. V. Krysko, T. Verfaillie et al., "A novel pathway combining calreticulin exposure and ATP secretion in immunogenic cancer cell death," EMBO Journal, vol. 31, no. 5, pp. 1062-1079, 2012.

[71] T. Panaretakis, O. Kepp, U. Brockmeier et al., "Mechanisms of pre-apoptotic calreticulin exposure in immunogenic cell death," EMBO Journal, vol. 28, no. 5, pp. 578-590, 2009.

[72] N. Casares, M. O. Pequignot, A. Tesniere et al., "Caspasedependent immunogenicity of doxorubicin-induced tumor cell death," The Journal of Experimental Medicine, vol. 202, no. 12, pp. 1691-1701, 2005.

[73] L. Apetoh, F. Ghiringhelli, A. Tesniere et al., "Toll-like receptor 4-dependent contribution of the immune system to anticancer chemotherapy and radiotherapy," Nature Medicine, vol. 13, no. 9, pp. 1050-1059, 2007.

[74] M. Wemeau, O. Kepp, A. Tesnière et al., "Calreticulin exposure on malignant blasts predicts a cellular anticancer immune response in patients with acute myeloid leukemia," Cell Death and Disease, vol. 1, no. 12, article e104, 2010.

[75] A. Pekáriková, D. Sánchez, L. Palová-Jelínková et al., "Calreticulin is a B cell molecular target in some gastrointestinal malignancies," Clinical and Experimental Immunology, vol. 160, no. 2, pp. 215-222, 2010.
[76] E. M. Tan, "Autoantibodies as reporters identifying aberrant cellular mechanisms in tumorigenesis," The Journal of Clinical Investigation, vol. 108, no. 10, pp. 1411-1415, 2001.

[77] J. Y. Zhang, C. A. Casiano, X. X. Peng, J. A. Koziol, E. K. L. Chan, and E. M. Tan, "Enhancement of antibody detection in cancer using panel of recombinant tumor-associated antigens," Cancer Epidemiology Biomarkers \& Prevention, vol. 12, no. 2, pp. 136-143, 2003.

[78] R. Bei, L. Masuelli, C. Palumbo, M. Modesti, and A. Modesti, "A common repertoire of autoantibodies is shared by cancer and autoimmune disease patients: inflammation in their induction and impact on tumor growth," Cancer Letters, vol. 281, no. 1, pp. $8-23,2009$.

[79] T. T. Tan and L. M. Coussens, "Humoral immunity, inflammation and cancer," Current Opinion in Immunology, vol. 19, no. 2, pp. 209-216, 2007.

[80] J. I. Ellyard, L. Simson, and C. R. Parish, "Th2-mediated antitumour immunity: friend or foe?” Tissue Antigens, vol. 70, no. 1, pp. 1-11, 2007.

[81] S. J. Gardai, K. A. McPhillips, S. C. Frasch et al., "Cellsurface calreticulin initiates clearance of viable or apoptotic cells through trans-activation of LRP on the phagocyte," Cell, vol. 123, no. 2, pp. 321-334, 2005.

[82] R. W. Vandivier, C. A. Ogden, V. A. Fadok et al., "Role of surfactant proteins $\mathrm{A}, \mathrm{D}$, and $\mathrm{Clq}$ in the clearance of apoptotic cells in vivo and in vitro: calreticulin and CD91 as a common collectin receptor complex," The Journal of Immunology, vol. 169, no. 7, pp. 3978-3986, 2002.

[83] A. W. Orr, C. A. Elzie, D. F. Kucik, and J. E. MurphyUllrich, "Thrombospondin signaling through the calreticulin/LDL receptor-related protein co-complex stimulates random and directed cell migration," Journal of Cell Science, vol. 116, no. 14, pp. 2917-2927, 2003.

[84] C. A. Ogden, A. DeCathelineau, P. R. Hoffmann et al., "C1q and mannose binding lectin engagement of cell surface calreticulin and CD91 initiates macropinocytosis and uptake of apoptotic cells," The Journal of Experimental Medicine, vol. 194, no. 6, pp. 781-795, 2001.

[85] C. Honoré, T. Hummelshoj, B. E. Hansen, H. O. Madsen, P. Eggleton, and P. Garred, "The innate immune component ficolin 3 (Hakata antigen) mediates the clearance of late apoptotic cells," Arthritis \& Rheumatism, vol. 56, no. 5, pp. 1598-1607, 2007.

[86] M. L. Jensen, C. Honoré, T. Hummelshøj, B. E. Hansen, H. O. Madsen, and P. Garred, "Ficolin-2 recognizes DNA and participates in the clearance of dying host cells," Molecular Immunology, vol. 44, no. 5, pp. 856-865, 2007.

[87] B. Berwin, J. P. Hart, S. Rice et al., "Scavenger receptora mediates gp96/GRP94 and calreticulin internalization by antigen-presenting cells," EMBO Journal, vol. 22, no. 22, pp. 6127-6136, 2003.

[88] B. Berwin, Y. Delneste, R. V. Lovingood, S. R. Post, and S. V. Pizzo, "SREC-I, a type F scavenger receptor, is an endocytic receptor for calreticulin," The Journal of Biological Chemistry, vol. 279, no. 49, pp. 51250-51257, 2004.

[89] S. Basu, R. J. Binder, T. Ramalingam, and P. K. Srivastava, "CD91 is a common receptor for heat shock proteins gp96, hsp90, hsp70, and calreticulin," Immunity, vol. 14, no. 3, pp. 303-313, 2001.

[90] S. Papp and M. Opas, "Sub-cellular distribution of calreticulina," in Calreticulin, P. Eggleton and M. Michalak, Eds., pp. 38-48, 
Springer, Berlin, Germany, 2nd edition, 2003, Molecular Biology Intelligence Unit.

[91] G. Zeng, M. E. Aldridge, X. Tian et al., "Dendritic cell surface calreticulin is a receptor for NY-ESO-1: direct interactions between tumor-associated antigen and the innate immune system," The Journal of Immunology, vol. 177, no. 6, pp. 3582-3589, 2006.

[92] F. A. Arosa, O. de Jesus, G. Porto, A. M. Carmo, and M. De Sousa, "Calreticulin is expressed on the cell surface of activated human peripheral blood $\mathrm{T}$ lymphocytes in association with major histocompatibility complex class I molecules," The Journal of Biological Chemistry, vol. 274, no. 24, pp. 16917-16922, 1999.

[93] D. Lanneau, M. Brunet, E. Frisan, E. Solary, M. Fontenay, and C. Garrido, "Heat shock proteins: essential proteins for apoptosis regulation: apoptosis review series," Journal of Cellular and Molecular Medicine, vol. 12, no. 3, pp. 743-761, 2008.

[94] A. Tesniere, T. Panaretakis, O. Kepp et al., "Molecular characteristics of immunogenic cancer cell death," Cell Death and Differentiation, vol. 15, no. 1, pp. 3-12, 2008.

[95] H. M. Beere, B. B. Wolf, K. Cain et al., "Heat-shock protein 70 inhibits apoptosis by preventing recruitment of procaspase- 9 to the Apaf-1 apoptosome," Nature Cell Biology, vol. 2, no. 8, pp. 469-475, 2000.

[96] L. Ravagnan, S. Gurbuxani, S. A. Susin et al., "Heat-shock protein 70 antagonizes apoptosis-inducing factor," Nature Cell Biology, vol. 3, no. 9, pp. 839-843, 2001.

[97] R. Wadhwa, T. Yaguchi, M. K. Hasan, Y. Mitsui, R. R. Reddel, and S. C. Kaul, "Hsp70 family member, mot2/mthsp70/GRP75, binds to the cytoplasmic sequestration domain of the p53 protein," Experimental Cell Research, vol. 274, no. 2, pp. 246-253, 2002.

[98] J. S. Lee, J. J. Lee, and J. S. Seo, "HSP70 deficiency results in activation of c-Jun $\mathrm{N}$-terminal kinase, extracellular signalregulated kinase, and caspase- 3 in hyperosmolarity-induced apoptosis," The Journal of Biological Chemistry, vol. 280, no. 8, pp. 6634-6641, 2005.

[99] A. R. Stankiewicz, G. Lachapelle, C. P. Z. Foo, S. M. Radicioni, and D. D. Mosser, "Hsp70 inhibits heat-induced apoptosis upstream of mitochondria by preventing Bax translocation," The Journal of Biological Chemistry, vol. 280, no. 46, pp. 38729-38739, 2005.

[100] P. Pandey, A. Saleh, A. Nakazawa et al., "Negative regulation of cytochrome c-mediated oligomerization of Apaf-1 and activation of procaspase- 9 by heat shock protein 90," EMBO Journal, vol. 19, no. 16, pp. 4310-4322, 2000.

[101] O. N. Ozes, L. D. Mayo, J. A. Gustin, S. R. Pfeffer, L. M. Pfeffer, and D. B. Donner, "NF- $\kappa$ B activation by tumour necrosis factor requires tie Akt serine- threonine kinase," Nature, vol. 401, no. 6748, pp. 82-85, 1999.

[102] H. Shi, T. Cao, J. E. Connolly et al., "Hyperthermia enhances CTL cross-priming," The Journal of Immunology, vol. 176, no. 4, pp. 2134-2141, 2006.

[103] D. Massé, F. Ebstein, G. Bougras, J. Harb, K. Meflah, and M. Grégoire, "Increased expression of inducible HSP70 in apoptotic cells is correlated with their efficacy for antitumor vaccine therapy," International Journal of Cancer, vol. 111, no. 4, pp. 575-583, 2004.

[104] N. Arispe, M. Doh, O. Simakova, B. Kurganov, and A. De Maio, "Hsc70 and Hsp70 interact with phosphatidylserine on the surface of PC12 cells resulting in a decrease of viability," FASEB Journal, vol. 18, no. 14, pp. 1636-1645, 2004.
[105] J. Bartunkov and R. Spisek, "Impact of tumour cell death on the activation of anti-tumour immune response," in Phagocytosis of Dying Cells, Science+Business Media B.V., D. V. Krysko and P. Vandenabeele, Eds., pp. 347-370, Springer Science, Business Media, Berlin, Germany, 2009.

[106] R. Spisek and M. V. Dhodapkar, "Towards a better way to die with chemotherapy: role of heat shock protein exposure on dying tumor cells," Cell Cycle, vol. 6, no. 16, pp. 1962-1965, 2007.

[107] A. D. H. Doody, J. T. Kovalchin, M. A. Mihalyo, A. T. Hagymasi, C. G. Drake, and A. J. Adler, "Glycoprotein 96 can chaperone both MHC class I- and class II-restricted epitopes for in vivo presentation, but selectively primes CD8+ T cell effector function," The Journal of Immunology, vol. 172, no. 10, pp. 6087-6092, 2004.

[108] R. J. Binder, N. E. Blachere, and P. K. Srivastava, "Heat shock protein-chaperoned peptides but not free peptides introduced into the cytosol are presented efficiently by major histocompatibility complex I molecules," The Journal of Biological Chemistry, vol. 276, no. 20, pp. 17163-17171, 2001.

[109] A. Asea, M. Rehli, E. Kabingu et al., "Novel signal transduction pathway utilized by extracellular HSP70. Role of toll-like receptor (TLR) 2 and TLR4," The Journal of Biological Chemistry, vol. 277, no. 17, pp. 15028-15034, 2002.

[110] A. Asea, S. K. Kraeft, E. A. Kurt-Jones et al., "HSP70 stimulates cytokine production through a CD 14-dependant pathway, demonstrating its dual role as a chaperone and cytokine," Nature Medicine, vol. 6, no. 4, pp. 435-442, 2000.

[111] Y. Wang, C. G. Kelly, M. Singh et al., "Stimulation of Th1polarizing cytokines, $\mathrm{C}-\mathrm{C}$ chemokines, maturation of dendritic cells, and adjuvant function by the peptide binding fragment of heat shock protein 70," The Journal of Immunology, vol. 169, no. 5, pp. 2422-2429, 2002.

[112] T. Lehner, Y. Wang, T. Whittall, E. McGowan, C. G. Kelly, and M. Singh, "Functional domains of HSP70 stimulate generation of cytokines and chemokines, maturation of dendritic and adjuvanticity," Biochemical Society Transactions, vol. 32, no. 4, pp. 629-632, 2004.

[113] H. Singh-Jasuja, R. E. M. Toes, P. Spee et al., "Cross-presentation of glycoprotein 96-associated antigens: on major histocompatibility complex class I molecules requires receptor-mediated endocytosis," The Journal of Experimental Medicine, vol. 191, no. 11, pp. 1965-1974, 2000.

[114] H. D. Hickman-Miller and W. H. Hildebrand, "The immune response under stress: the role of HSP-derived peptides," Trends in Immunology, vol. 25, no. 8, pp. 427-433, 2004.

[115] G. Multhoff, L. Mizzen, C. C. Winchester et al., "Heat shock protein 70 (Hsp70) stimulates proliferation and cytolytic activity of natural killer cells," Experimental Hematology, vol. 27, no. 11, pp. 1627-1636, 1999.

[116] H. Feng, Y. Zeng, M. W. Graner, A. Likhacheva, and E. Katsanis, "Exogenous stress proteins enhance the immunogenicity of apoptotic tumor cells and stimulate antitumor immunity," Blood, vol. 101, no. 1, pp. 245-252, 2003.

[117] A. Barreto, J. M. Gonzalez, E. Kabingu, A. Asea, and S. Fiorentino, "Stress-induced release of HSC70 from human tumors," Cellular Immunology, vol. 222, no. 2, pp. 97-104, 2003.

[118] C. Yang and P. D. Robbins, "The roles of tumour-derived exosomes in cancer pathogenesis," Clinical and Developmental Immunology, vol. 2011, Article ID 842849, 11 pages, 2011.

[119] R. Gastpar, M. Gehrmann, M. A. Bausero et al., "Heat shock protein 70 surface-positive tumor exosomes stimulate 
migratory and cytolytic activity of natural killer cells," Cancer Research, vol. 65, no. 12, pp. 5238-5247, 2005.

[120] M. A. Bausero, R. Gastpar, G. Multhoff, and A. Asea, "Alternative mechanism by which IFN- $\gamma$ enhances tumor recognition: active release of heat shock protein 72," The Journal of Immunology, vol. 175, no. 5, pp. 2900-2912, 2005.

[121] G. I. Lancaster and M. A. Febbraio, "Exosome-dependent trafficking of HSP70: a novel secretory pathway for cellular stress proteins," The Journal of Biological Chemistry, vol. 280, no. 24, pp. 23349-23355, 2005.

[122] W. van Eden, R. Spiering, F. Broere, and R. van der Zee, "A case of mistaken identity: HSPs are no DAMPs but DAMPERs," Cell Stress and Chaperones, vol. 17, no. 3, pp. 281-292, 2012.

[123] H. Kono and K. L. Rock, "How dying cells alert the immune system to danger," Nature Reviews Immunology, vol. 8, no. 4, pp. 279-289, 2008.

[124] G. Y. Chen and G. Nuñez, "Sterile inflammation: sensing and reacting to damage," Nature Reviews Immunology, vol. 10, no. 12, pp. 826-837, 2010.

[125] R. P. A. Wallin, A. Lundqvist, S. H. Moré, A. von Bonin, R. Kiessling, and H. G. Ljunggren, "Heat-shock proteins as activators of the innate immune system," Trends in Immunology, vol. 23, no. 3, pp. 130-135, 2002.

[126] H. Bendz, B. C. Marincek, F. Momburg et al., "Calcium signaling in dendritic cells by human or mycobacterial Hsp70 is caused by contamination and is not required for Hsp70mediated enhancement of cross-presentation," The Journal of Biological Chemistry, vol. 283, no. 39, pp. 26477-26483, 2008.

[127] A. Motta, C. Schmitz, L. Rodrigues et al., "Mycobacterium tuberculosis heat-shock protein 70 impairs maturation of dendritic cells from bone marrow precursors, induces interleukin-10 production and inhibits T-cell proliferation in vitro," Immunology, vol. 121, no. 4, pp. 462-472, 2007.

[128] M. V. Dhodapkar, K. M. Dhodapkar, and Z. Li, "Role of chaperones and $\mathrm{F} c \gamma \mathrm{R}$ in immunogenic death," Current Opinion in Immunology, vol. 20, no. 5, pp. 512-517, 2008.

[129] H. Wang, O. Bloom, M. Zhang et al., "HMG-1 as a late mediator of endotoxin lethality in mice," Science, vol. 285, no. 5425, pp. 248-251, 1999.

[130] H. Kazama, J. E. Ricci, J. M. Herndon, G. Hoppe, D. R. Green, and T. A. Ferguson, "Induction of immunological tolerance by apoptotic cells requires caspase-dependent oxidation of highmobility group box-1 protein," Immunity, vol. 29, no. 1, pp. 21-32, 2008.

[131] S. Guazzi, A. Strangio, A. T. Franzi, and M. E. Bianchi, "HMGB1, an architectural chromatin protein and extracellular signalling factor, has a spatially and temporally restricted expression pattern in mouse brain," Gene Expression Patterns, vol. 3, no. 1, pp. 29-33, 2003.

[132] T. Vaccari, M. Beltrame, S. Ferrari, and M. E. Bianchi, "Hmg4, a new member of the Hmg1/2 gene family," Genomics, vol. 49, no. 2, pp. 247-252, 1998.

[133] L. Ronfani, M. Ferraguti, L. Croci et al., "Reduced fertility and spermatogenesis defects in mice lacking chromosomal protein Hmgb2," Development, vol. 128, no. 8, pp. 1265-1273, 2001.

[134] R. Palumbo, M. Sampaolesi, F. De Marchis et al., "Extracellular HMGB1, a signal of tissue damage, induces mesoangioblast migration and proliferation," Journal of Cell Biology, vol. 164, no. 3, pp. 441-449, 2004.

[135] J. S. Park, D. Svetkauskaite, Q. He et al., "Involvement of toll-like receptors 2 and 4 in cellular activation by high mobility group box 1 protein," The Journal of Biological Chemistry, vol. 279, no. 9, pp. 7370-7377, 2004.

[136] D. Yang, Q. Chen, H. Yang, K. J. Tracey, M. Bustin, and J. J. Oppenheim, "High mobility group box-1 protein induces the migration and activation of human dendritic cells and acts as an alarmin," Journal of Leukocyte Biology, vol. 81, no. 1, pp. 59-66, 2007.

[137] V. V. Orlova, E. Y. Choi, C. Xie et al., "A novel pathway of HMGB1-mediated inflammatory cell recruitment that requires Mac-1-integrin," EMBO Journal, vol. 26, no. 4, pp. 1129-1139, 2007.

[138] D. Tang, R. Kang, H. J. Zeh III, and M. T. Lotze, "High-mobility group box 1 and cancer," Biochimica et Biophysica Acta, vol. 1799, no. 1-2, pp. 131-140, 2010.

[139] P. Scaffidi, T. Misteli, and M. E. Bianchi, "Release of chromatin protein HMGB1 by necrotic cells triggers inflammation," Nature, vol. 418, no. 6894, pp. 191-195, 2002.

[140] J. Thorburn, H. Horita, J. Redzic, K. Hansen, A. E. Frankel, and A. Thorburn, "Autophagy regulates selective HMGB1 release in tumor cells that are destined to die," Cell Death and Differentiation, vol. 16, no. 1, pp. 175-183, 2009.

[141] J. J. Choi, C. F. Reich III, and D. S. Pisetsky, "Release of DNA from dead and dying lymphocyte and monocyte cell lines in vitro," Scandinavian The Journal of Immunology, vol. 60, no. 1-2, pp. 159-166, 2004.

[142] C. W. Bell, W. Jiang, C. F. Reich III, and D. S. Pisetsky, "The extracellular release of HMGB1 during apoptotic cell death," American Journal of Physiology, vol. 291, no. 6, pp. C1318-C1325, 2006.

[143] J. Tian, A. M. Avalos, S. Y. Mao et al., “Toll-like receptor 9dependent activation by DNA-containing immune complexes is mediated by HMGB1 and RAGE," Nature Immunology, vol. 8, no. 5, pp. 487-496, 2007.

[144] L. Liu, M. Yang, R. Kang et al., "DAMP-mediated autophagy contributes to drug resistance," Autophagy, vol. 7, no. 1, pp. 112-114, 2011.

[145] L. Liu, M. Yang, R. Kang et al., "HMGB1-induced autophagy promotes chemotherapy resistance in leukemia cells," Leukemia, vol. 25, no. 1, pp. 23-31, 2011.

[146] D. Tang, R. Kang, C. W. Cheh et al., "HMGB1 release and redox regulates autophagy and apoptosis in cancer cells," Oncogene, vol. 29, no. 38, pp. 5299-5310, 2010.

[147] D. V. Krysko, L. Leybaert, P. Vandenabeele, and K. D’Herde, "Gap junctions and the propagation of cell survival and cell death signals," Apoptosis, vol. 10, no. 3, pp. 459-469, 2005.

[148] E. Decrock, M. Vinken, E. De Vuyst et al., "Connexin-related signaling in cell death: to live or let die?" Cell Death and Differentiation, vol. 16, no. 4, pp. 524-536, 2009.

[149] Y. Shi, W. Zheng, and K. L. Rock, "Cell injury releases endogenous adjuvants that stimulate cytotoxic T cell responses," Proceedings of the National Academy of Sciences of the United States of America, vol. 97, no. 26, pp. 14590-14595, 2000.

[150] Y. Shi and K. L. Rock, "Cell death releases endogenous adjuvants that selectively enhance immune surveillance of particulate antigens," European The Journal of Immunology, vol. 32, no. 1, pp. 155-162, 2002.

[151] D. Ferrari, S. Wesselborg, M. K. A. Bauer, and K. SchulzeOsthoff, "Extracellular ATP activates transcription factor NF$\kappa \mathrm{B}$ through the $\mathrm{P} 2 \mathrm{Z}$ purinoreceptor by selectively targeting NF$\kappa \mathrm{B}$ p65 (RelA)," The Journal of Cell Biology, vol. 139, no. 7, pp. 1635-1643, 1997. 
[152] C. E. Stout, J. L. Costantin, C. C. G. Naus, and A. C. Charles, "Intercellular calcium signaling in astrocytes via ATP release through connexin hemichannels," The Journal of Biological Chemistry, vol. 277, no. 12, pp. 10482-10488, 2002.

[153] Z. Zhang, G. Chen, W. Zhou et al., "Regulated ATP release from astrocytes through lysosome exocytosis," Nature Cell Biology, vol. 9, no. 8, pp. 945-953, 2007.

[154] T. Eigenbrod, J. H. Park, J. Harder, Y. Iwakura, and G. Núñez, "Cutting edge: critical role for mesothelial cells in necrosis-induced inflammation through the recognition of IL$1 \alpha$ released from dying cells," The Journal of Immunology, vol. 181, no. 12, pp. 8194-8198, 2008.

[155] T. Vanden Berghe, M. Kalai, G. Denecker, A. Meeus, X. Saelens, and P. Vandenabeele, "Necrosis is associated with IL-6 production but apoptosis is not," Cellular Signalling, vol. 18, no. 3, pp. 328-335, 2006.

[156] B. Bottazzi, C. Garlanda, G. Salvatori, P. Jeannin, A. Manfredi, and A. Mantovani, "Pentraxins as a key component of innate immunity," Current Opinion in Immunology, vol. 18, no. 1, pp. 10-15, 2006.

[157] P. A. Oldenborg, H. D. Gresham, and F. P. Lindberg, "CD47signal regulatory protein $\alpha(\operatorname{SIRP} \alpha)$ regulates $\mathrm{Fc} \gamma$ and complement receptor-mediated phagocytosis," The Journal of Experimental Medicine, vol. 193, no. 7, pp. 855-862, 2001.

[158] C. Castelli, A. T. Ciupitu, F. Rini et al., "Human heat shock protein 70 peptide complexes specifically activate antimelanoma $t$ cells," Cancer Research, vol. 61, no. 1, pp. 222-227, 2001.

[159] L. Delamarre, R. Couture, I. Mellman, and E. S. Trombetta, "Enhancing immunogenicity by limiting susceptibility to lysosomal proteolysis," The Journal of Experimental Medicine, vol. 203, no. 9, pp. 2049-2055, 2006.

[160] A. Shiratsuchi, I. Watanabe, O. Takeuchi, S. Akira, and Y. Nakanishi, "Inhibitory effect of Toll-like receptor 4 on fusion between phagosomes and endosomes/lysosomes in macrophages," The Journal of Immunology, vol. 172, no. 4, pp. 2039-2047, 2004.

[161] F. Ghiringhelli, L. Apetoh, A. Tesniere et al., "Activation of the NLRP3 inflammasome in dendritic cells induces IL1beta-dependent adaptive immunity against tumors," Nature Medicine, vol. 15, no. 10, pp. 1170-1178, 2009.

[162] E. Latz, "The inflammasomes: mechanisms of activation and function," Current Opinion in Immunology, vol. 22, no. 1, pp. 28-33, 2010.

[163] L. Franchi, T. Eigenbrod, R. Muñoz-Planillo, and G. Nuñez, "The inflammasome: a caspase-1-activation platform that regulates immune responses and disease pathogenesis," Nature Immunology, vol. 10, no. 3, pp. 241-247, 2009.

[164] M. R. Elliott, F. B. Chekeni, P. C. Trampont et al., "Nucleotides released by apoptotic cells act as a find-me signal to promote phagocytic clearance," Nature, vol. 461, no. 7261, pp. 282-286, 2009.

[165] K. Pizova, K. Tomankova, A. Daskova, S. Binder, R. Bajgar, and H. Kolarova, "Photodynamic therapy for enhancing antitumour immunity," Biomedical Papers of the Medical Faculty of the University Palacky, Olomouc, Czech Republic, vol. 156, no. 2, pp. 93-102, 2012.

[166] L. Zitvogel, L. Apetoh, F. Ghiringhelli, F. André, A. Tesniere, and G. Kroemer, "The anticancer immune response: indispensable for therapeutic success?" The Journal of Clinical Investigation, vol. 118, no. 6, pp. 1991-2001, 2008.
[167] A. D. Garg, D. V. Krysko, P. Vandenabeele, and P. Agostinis, "DAMPs and PDT-mediated photo-oxidative stress: exploring the unknown," Photochemical \& Photobiological Sciences, vol. 10, no. 5, pp. 670-680, 2011.

[168] M. Olivo, R. Bhuvaneswari, S. S. Lucky, N. Dendukuri, and P. Soo-Ping Thong, "Targeted therapy of cancer using photodynamic therapy in combination with multi-faceted anti-tumor modalities," Pharmaceuticals, vol. 3, no. 5, pp. 1507-529, 2010.

[169] S. O. Gollnick and C. M. Brackett, "Enhancement of anti-tumor immunity by photodynamic therapy," Immunologic Research, vol. 46, no. 1-3, pp. 216-226, 2010.

[170] D. G. DeNardo, P. Andreu, and L. M. Coussens, "Interactions between lymphocytes and myeloid cells regulate pro-versus anti-tumor immunity," Cancer and Metastasis Reviews, vol. 29, no. 2, pp. 309-316, 2010.

[171] S. I. Grivennikov, F. R. Greten, and M. Karin, "Immunity, inflammation, and cancer," Cell, vol. 140, no. 6, pp. 883-899, 2010.

[172] A. E. Karnoub and R. A. Weinberg, "Chemokine networks and breast cancer metastasis," Breast Disease, vol. 26, no. 1, pp. 75-85, 2006.

[173] B. Z. Qian and J. W. Pollard, "Macrophage diversity enhances tumor progression and metastasis," Cell, vol. 141, no. 1, pp. 39-51, 2010.

[174] S. W. Ryter and C. J. Gomer, "Nuclear factor kappa B binding activity in mouse L1210 cells following photofrin II-mediated photosensitization," Photochemistry and Photobiology, vol. 58, no. 5, pp. 753-756, 1993.

[175] S. Legrand-Poels, V. Bours, B. Piret et al., "Transcription factor $\mathrm{NF}-\kappa \mathrm{B}$ is activated by photosensitization generating oxidative DNA damages," The Journal of Biological Chemistry, vol. 270, no. 12, pp. 6925-6934, 1995.

[176] J. Y. Matroule, G. Bonizzi, P. Morlière et al., "Pyropheophorbide-a methyl ester-mediated photosensitization activates transcription factor NF- $\kappa \mathrm{B}$ through the interleukin-1 receptordependent signaling pathway," The Journal of Biological Chemistry, vol. 274, no. 5, pp. 2988-3000, 1999.

[177] D. J. Granville, C. M. Carthy, H. Jiang et al., "Nuclear factor$\kappa \mathrm{B}$ activation by the photochemotherapeutic agent verteporfin," Blood, vol. 95, no. 1, pp. 256-262, 2000.

[178] G. Kick, G. Messer, A. Goetz, G. Plewig, and P. Kind, "Photodynamic therapy induces expression of interleukin 6 by activation of AP-1 but not NF- $\kappa$ B DNA binding," Cancer Research, vol. 55 , no. 11, pp. 2373-2379, 1995.

[179] S. O. Gollnick, B. Y. Lee, L. Vaughan, B. Owczarczak, and B. W. Henderson, "Activation of the IL-10 gene promoter following photodynamic therapy of murine keratinocytes," Photochemistry and Photobiology, vol. 73, no. 2, pp. 170-177, 2001.

[180] M. Firczuk, D. Nowis, and J. Gołb, "PDT-induced inflammatory and host responses," Photochemical \& Photobiological Sciences, vol. 10, no. 5, pp. 653-663, 2011.

[181] I. Cecic and M. Korbelik, "Mediators of peripheral blood neutrophilia induced by photodynamic therapy of solid tumors," Cancer Letters, vol. 183, no. 1, pp. 43-51, 2002.

[182] I. Cecic, C. S. Parkins, and M. Korbelik, "Induction of systemic neutrophil response in mice by photodynamic therapy of solid tumors," Photochemistry and Photobiology, vol. 74, no. 5, pp. 712-720, 2001.

[183] G. Krosl, M. Korbelik, and G. J. Dougherty, "Induction of immune cell infiltration into murine SCCVII tumour by photofrin-based photodynamic therapy," British Journal of Cancer, vol. 71, no. 3, pp. 549-555, 1995. 
[184] H. S. de Bruijn, W. Sluiter, A. van der Ploeg-van den Heuvel, H. J. C. M. Sterenborg, and D. J. Robinson, "Evidence for a bystander role of neutrophils in the response to systemic 5aminolevulinic acid-based photodynamic therapy," Photodermatology Photoimmunology and Photomedicine, vol. 22, no. 5, pp. 238-246, 2006.

[185] M. Korbelik, J. Sun, I. Cecic, and K. Serrano, "Adjuvant treatment for complement activation increases the effectiveness of photodynamic therapy of solid tumors," Photochemical \& Photobiological Sciences, vol. 3, no. 8, pp. 812-816, 2004.

[186] I. Cecic, K. Serrano, M. Gyongyossy-Issa, and M. Korbelik, "Characteristics of complement activation in mice bearing Lewis lung carcinomas treated by photodynamic therapy," Cancer Letters, vol. 225, no. 2, pp. 215-223, 2005.

[187] M. Korbelik and I. Cecic, "Complement activation cascade and its regulation: relevance for the response of solid tumors to photodynamic therapy," Journal of Photochemistry and Photobiology B, vol. 93, no. 1, pp. 53-59, 2008.

[188] I. Cecic and M. Korbelik, "Deposition of complement proteins on cells treated by photodynamic therapy in vitro," Journal of Environmental Pathology, Toxicology and Oncology, vol. 25, no. 1-2, pp. 189-203, 2006.

[189] I. Cecic, J. Sun, and M. Korbelik, "Role of complement anaphylatoxin $\mathrm{C} 3 \mathrm{a}$ in photodynamic therapy-elicited engagement of host neutrophils and other immune cells," Photochemistry and Photobiology, vol. 82, no. 2, pp. 558-562, 2006.

[190] B. Stott and M. Korbelik, "Activation of complement C3, C5, and C9 genes in tumors treated by photodynamic therapy," Cancer Immunology, Immunotherapy, vol. 56, no. 5, pp. 649-658, 2007.

[191] J. R. Dunkelberger and W. C. Song, "Complement and its role in innate and adaptive immune responses," Cell Research, vol. 20, no. 1, pp. 34-50, 2010.

[192] E. Kabingu, L. Vaughan, B. Owczarczak, K. D. Ramsey, and S. O. Gollnick, "CD8+ T cell-mediated control of distant tumours following local photodynamic therapy is independent of CD4+ T cells and dependent on natural killer cells," British Journal of Cancer, vol. 96, no. 12, pp. 1839-1848, 2007.

[193] P. S. P. Thong, K. W. Ong, N. S. G. Goh et al., "Photodynamictherapy-activated immune response against distant untreated tumours in recurrent angiosarcoma," The Lancet Oncology, vol. 8, no. 10, pp. 950-952, 2007.

[194] E. Kabingu, A. R. Oseroff, G. E. Wilding, and S. O. Gollnick, "Enhanced systemic immune reactivity to a basal cell carcinoma associated antigen following photodynamic therapy," Clinical Cancer Research, vol. 15, no. 13, pp. 4460-4466, 2009.

[195] P. Mroz, A. Szokalska, M. X. Wu, and M. R. Hamblin, "Photodynamic therapy of tumors can lead to development of systemic antigen-specific immune response," PLoS ONE, vol. 5, no. 12, Article ID e15194, 2010.

[196] S. O. Gollnick, D. A. Musser, A. R. Oseroff, L. Vaughan, B. Owczarczak, and B. W. Henderson, "IL-10 does not play a role in cutaneous Photofrin photodynamic therapy-induced suppression of the contact hypersensitivity response," Photochemistry and Photobiology, vol. 74, no. 6, pp. 811-816, 2001.

[197] N. Yusuf, S. K. Katiyar, and C. A. Elmets, “The immunosuppressive effects of phthalocyanine photodynamic therapy in mice are mediated by $\mathrm{CD} 4+$ and $\mathrm{CD} 8+\mathrm{T}$ cells and can be adoptively transferred to naive recipients," Photochemistry and Photobiology, vol. 84, no. 2, pp. 366-370, 2008.

[198] J. A. Bluestone and Q. Tang, "How do CD4+CD25+ regulatory T cells control autoimmunity?" Current Opinion in Immunology, vol. 17, no. 6, pp. 638-642, 2005.
[199] J. C. Marie, J. J. Letterio, M. Gavin, and A. Y. Rudensky, “TGF$\beta 1$ maintains suppressor function and Foxp3 expression in CD4 +CD25+ regulatory T cells," The Journal of Experimental Medicine, vol. 201, no. 7, pp. 1061-1067, 2005.

[200] F. Ghiringhelli, P. E. Puig, S. Roux et al., “Tumor cells convert immature myeloid dendritic cells into TGF-beta-secreting cells inducing CD4+CD25+ regulatory $\mathrm{T}$ cell proliferation," The Journal of Experimental Medicine, vol. 202, no. 7, pp. 919-929, 2005.

[201] M. Veldhoen, H. Moncrieffe, R. J. Hocking, C. J. Atkins, and B. Stockinger, "Modulation of dendritic cell function by naive and regulatory CD4+ T cells," The Journal of Immunology, vol. 176, no. 10, pp. 6202-6210, 2006.

[202] A. P. Castano, P. Mroz, M. X. Wu, and M. R. Hamblin, "Photodynamic therapy plus low-dose cyclophosphamide generates antitumor immunity in a mouse model," Proceedings of the National Academy of Sciences of the United States of America, vol. 105, no. 14, pp. 5495-5500, 2008.

[203] M. Korbelik, J. Sun, and I. Cecic, "Photodynamic therapyinduced cell surface expression and release of heat shock proteins: relevance for tumor response," Cancer Research, vol. 65, no. 3, pp. 1018-1026, 2005.

[204] A. D. Garg, D. Nowis, J. Golab, P. Vandenabeele, D. V. Krysko, and P. Agostinis, "Immunogenic cell death, DAMPs and anticancer therapeutics: an emerging amalgamation," Biochimica et Biophysica Acta, vol. 1805, no. 1, pp. 53-71, 2010.

[205] M. Korbelik, W. Zhang, and S. Merchant, "Involvement of damage-associated molecular patterns in tumor response to photodynamic therapy: surface expression of calreticulin and high-mobility group box-1 release," Cancer Immunology, Immunotherapy, vol. 60, no. 10, pp. 1431-1437, 2011.

[206] F. Zhou, D. Xing, and W. R. Chen, "Regulation of HSP70 on activating macrophages using PDT-induced apoptotic cells," International Journal of Cancer, vol. 125, no. 6, pp. 1380-1389, 2009.

[207] S. Mitra, B. R. Giesselman, F. J. De Jesús-Andino, and T. H. Foster, "Tumor response to mTHPC-mediated photodynamic therapy exhibits strong correlation with extracellular release of HSP70," Lasers in Surgery and Medicine, vol. 43, no. 7, pp. 632-643, 2011.

[208] N. Etminan, C. Peters, D. Lakbir et al., "Heat-shock protein 70-dependent dendritic cell activation by 5 -aminolevulinic acid-mediated photodynamic treatment of human glioblastoma spheroids in vitro," British Journal of Cancer, vol. 105, no. 7, pp. 961-969, 2011.

[209] M. Korbelik and J. Sun, "Photodynamic therapy-generated vaccine for cancer therapy," Cancer Immunology, Immunotherapy, vol. 55, no. 8, pp. 900-909, 2006.

[210] A. D. Garg, D. V. Krysko, P. Vandenabeele, and P. Agostinis, "Hypericin-based photodynamic therapy induces surface exposure of damage-associated molecular patterns like HSP70 and calreticulina," Cancer Immunology Immunotherapy, vol. 61, no. 2, pp. 215-221, 2012.

[211] L. Aymeric, L. Apetoh, F. Ghiringhelli et al., "Tumor cell death and ATP release prime dendritic cells and efficient anticancer immunity," Cancer Research, vol. 70, no. 3, pp. 855-858, 2010. 

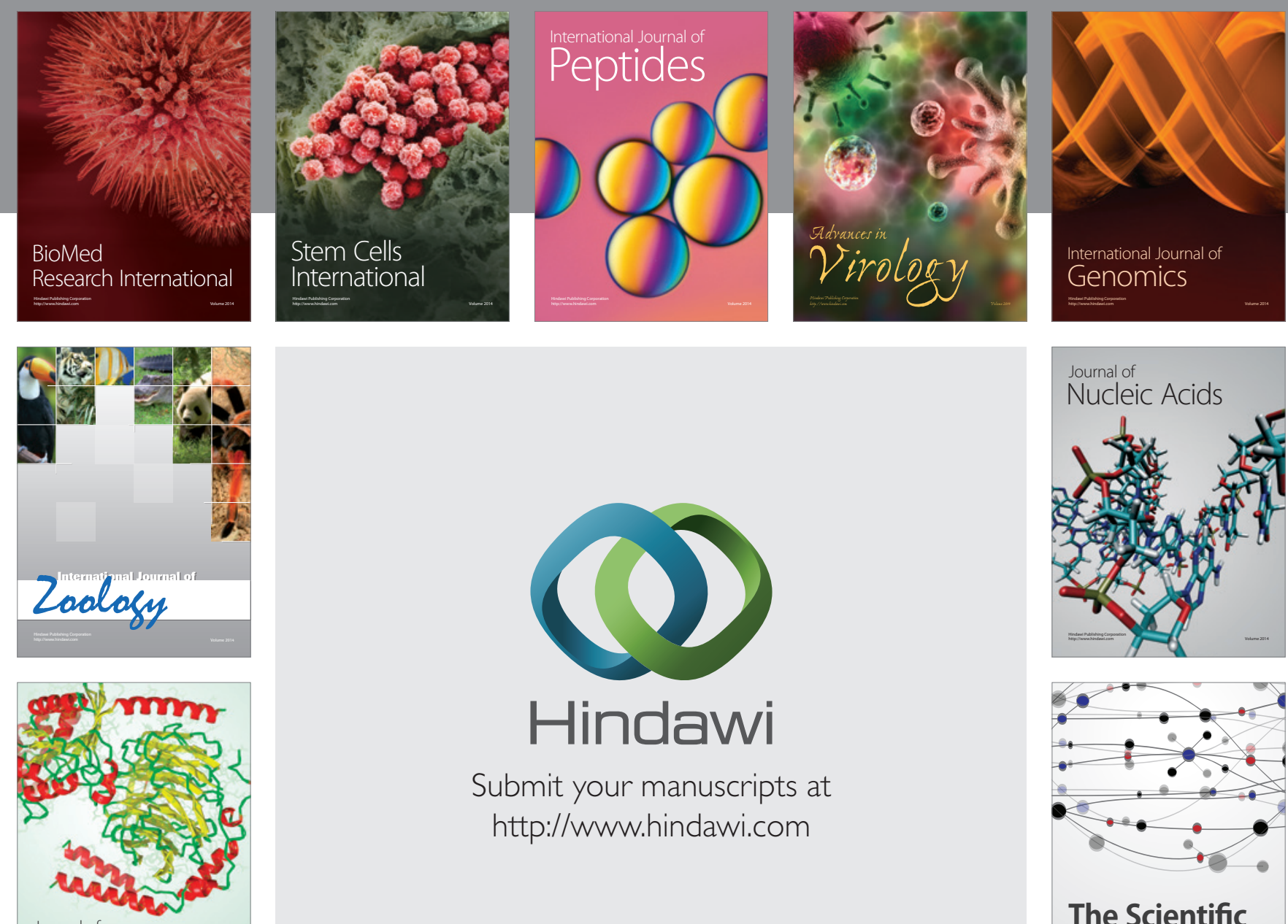

Submit your manuscripts at

http://www.hindawi.com

Journal of
Signal Transduction
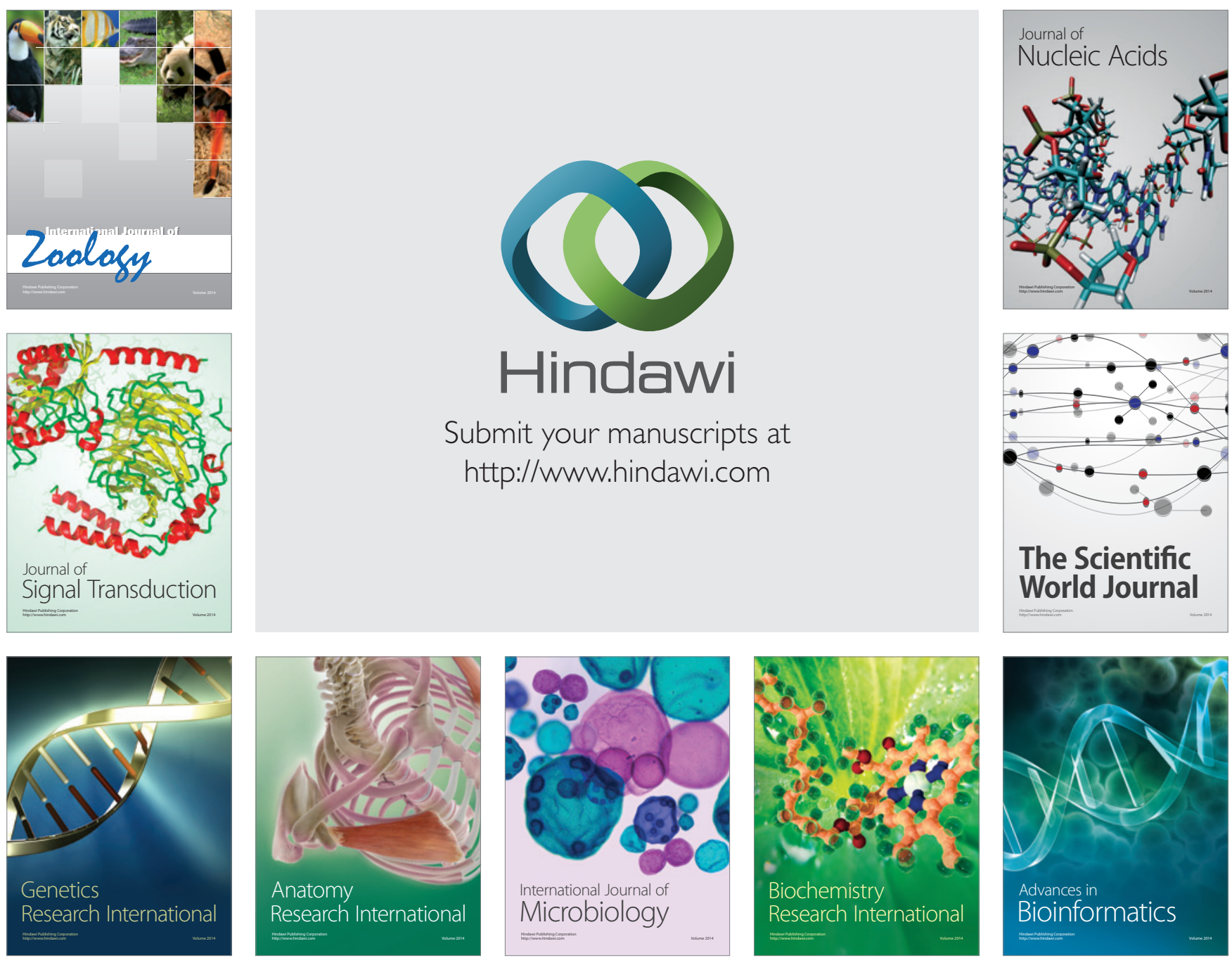

The Scientific World Journal
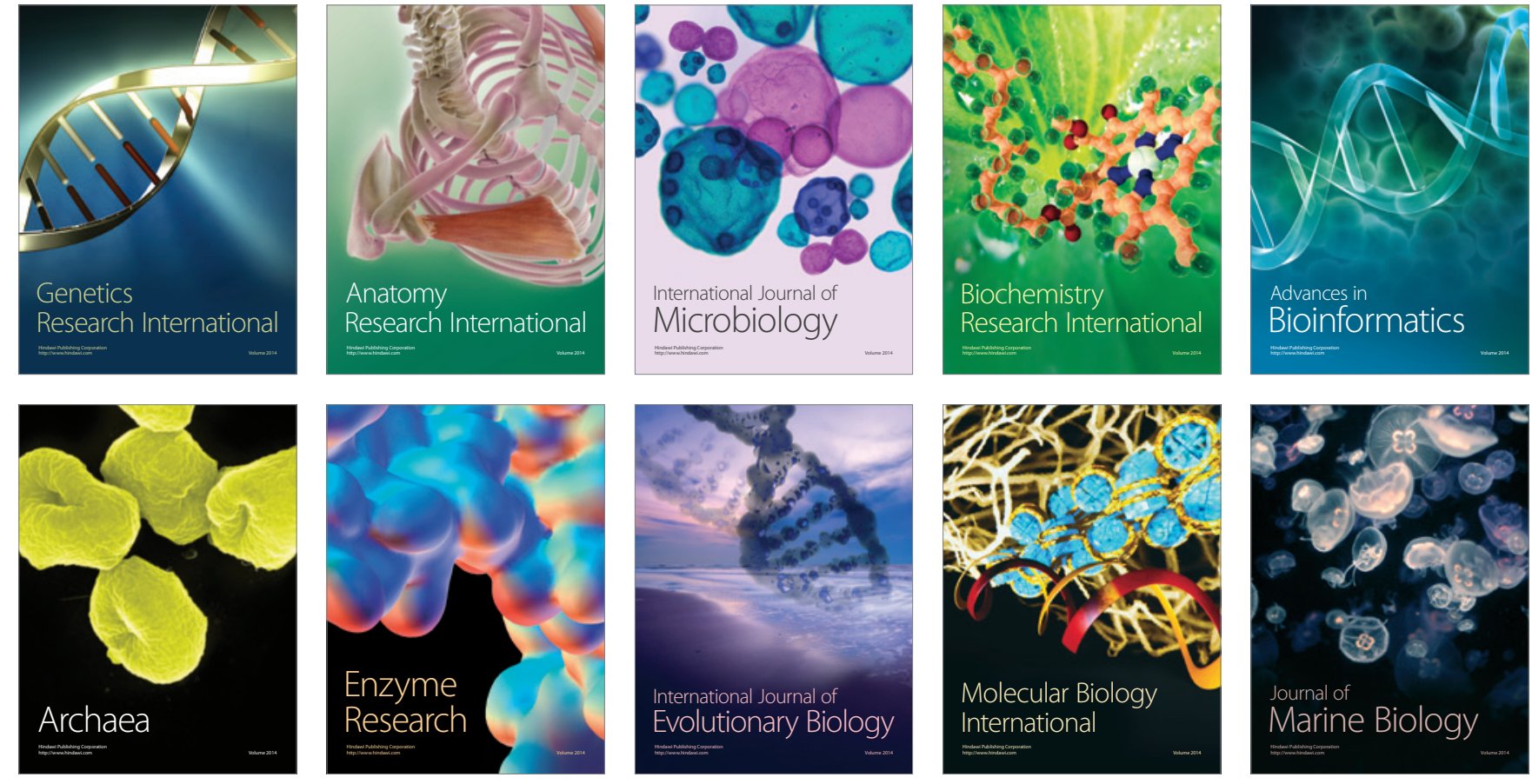